EDITORA

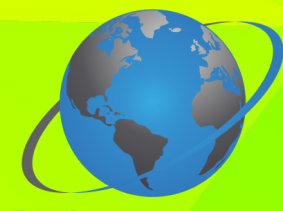

OMNIS SCIENTIA

\title{
ANAIS DA XIX SEMANA
}

\section{DA FISIOTERAPIA}

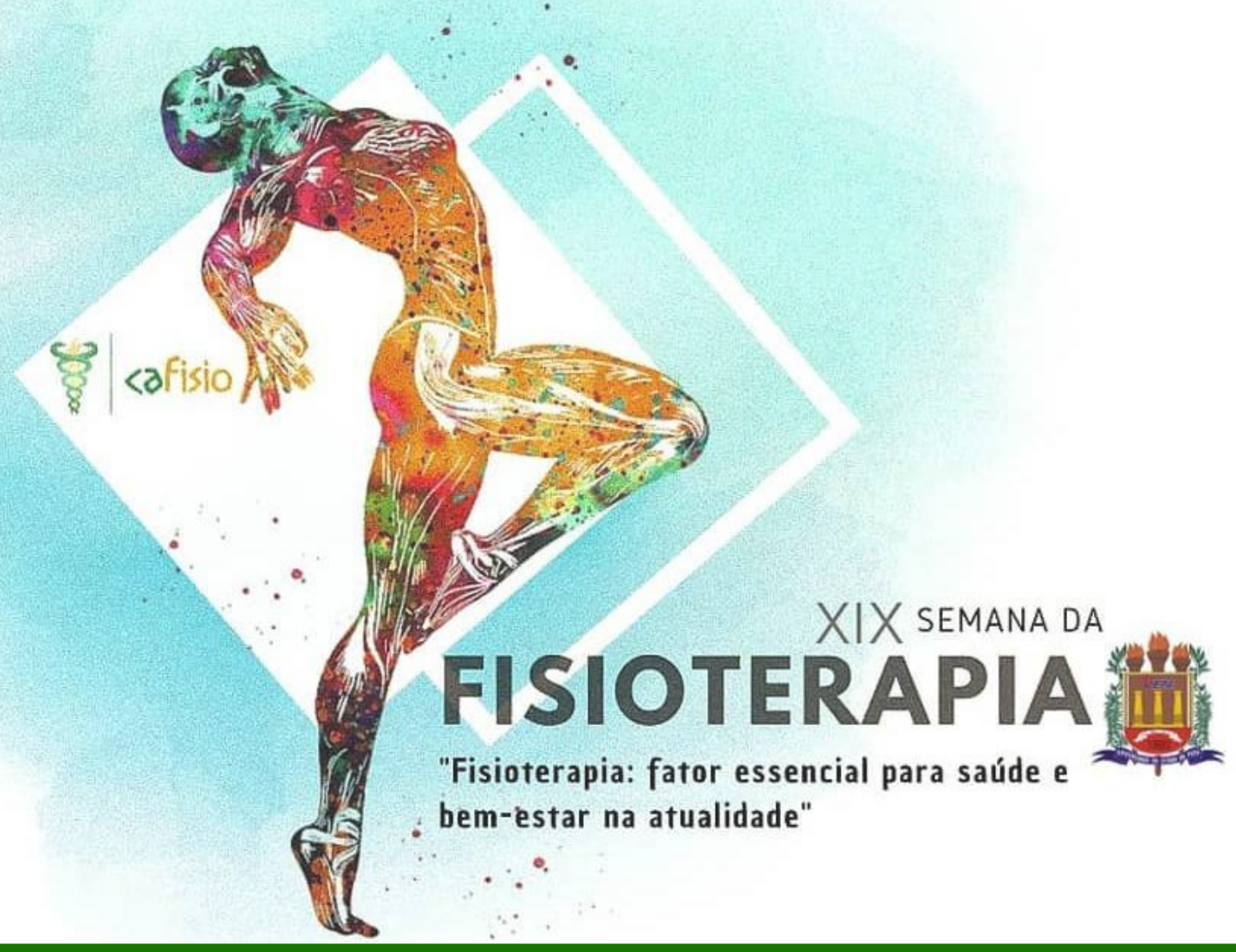


EDITORA

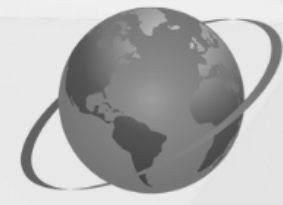

OMNIS SCIENTIA

\section{ANAIS DA XIX SEMANA}

DA FISIOTERAPIA

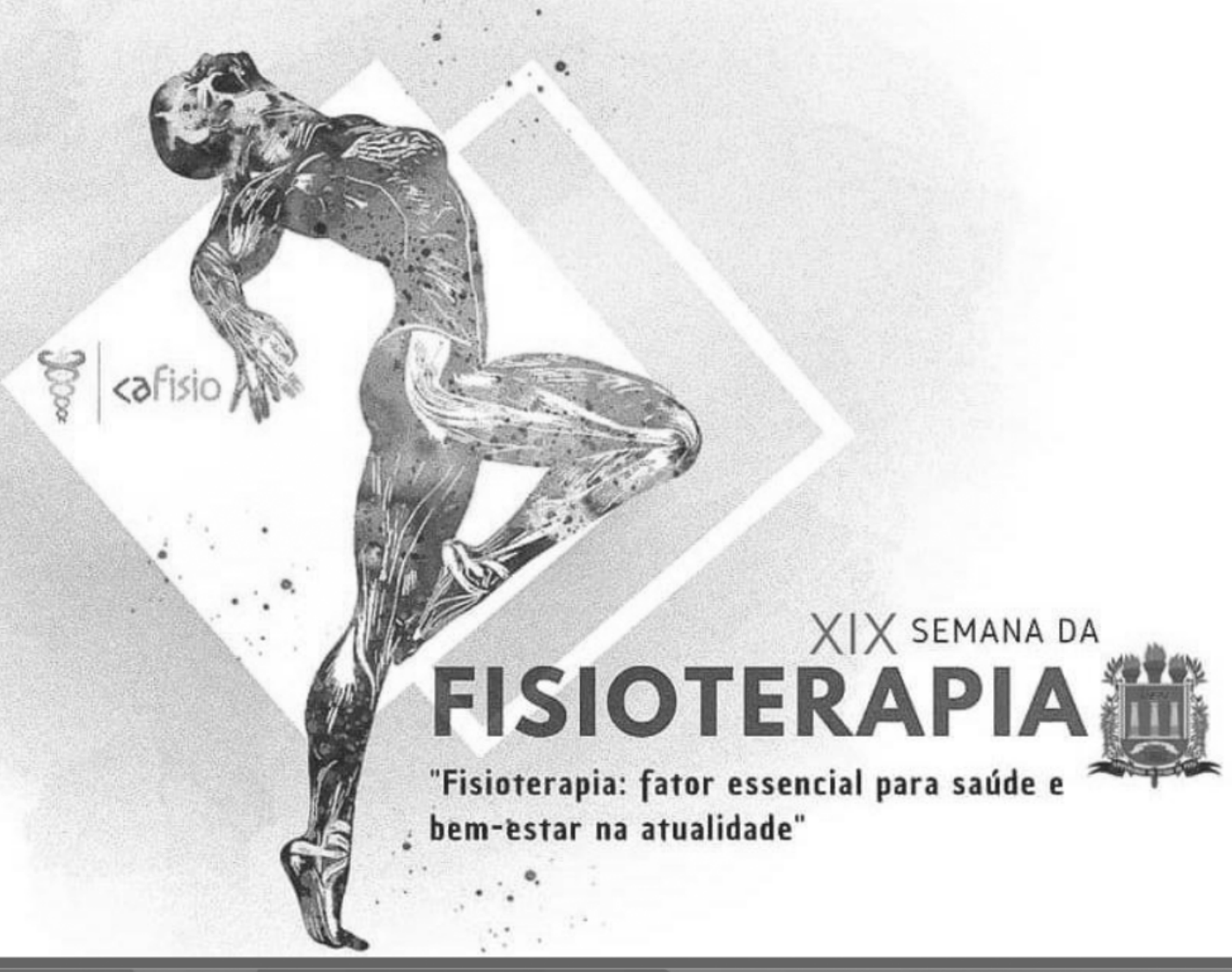


Editora Omnis Scientia

\section{ANAIS DA XIX SEMANA DA FISIOTERAPIA}

Volume 1

$1^{\text {a }}$ Edição

TRIUNFO - PE 


\section{Coordenador de Publicação}

Daniel Luís Viana Cruz

\section{Coordenadores do evento}

Davi Silva de Sousa

Israel Clemeson Moutinho Leite

Jennifer Maia Pessoa

\section{Comissão organizadora}

Davi Silva de Sousa

Israel Clemeson Moutinho Leite

Jennifer Maia Pessoa

Gustavo Antônio Tavares Picanço

Lorena Maria Souza da Silva

Sara Farias Oliveira

Juliana Nascimento da Silva

Sandro Júnio Assunção Amazonas

Érica da Silva Nascimento

Flávia Hortência Gomes de Oliveira

\section{Comissão científica}

Israel Clemeson Moutinho Leite

Lorena Maria Souza da Silva

Davi Silva de Sousa

Jennifer Maia Pessoa

\section{Banca examinadora}

Mariana dos Anjos Furtado de Sá

Renata Pessoa Portela

Tiago Santos Silveira

\section{Palestrantes}

Aline Miranda Ferreira 
Daniel da Cunha Ribeiro

Elidiane Moreira Kono

Erica Feio Carneiro Nunes

Evelim Leal de Freitas Dantas Gomes

João Victor Maciel Mendes

Jorge Carlos M Nascimento Junior

Kamila Teixeira

Lucas Garcia Costa

Mariana dos Anjos Furtado de Sá

Marina Silva Nicolau Taketomi

Paulo Henrique Ramos Pimentel

Priscila Bezerra Lima

Renata Pessoa Portela

Imagem de Capa

Freepik

\section{Edição de Arte}

Vileide Vitória Larangeira Amorim

\section{Revisão}

Os autores

\section{(9) $\mathbb{\oplus \Theta \Theta}$}

Este trabalho está licenciado com uma Licença Creative Commons - Atribuição-NãoComercialSemDerivações 4.0 Internacional.

O conteúdo abordado nos artigos, seus dados em sua forma, correção e confiabilidade são de responsabilidade exclusiva dos autores. 
Dados Internacionais de Catalogação na Publicação (CIP) (eDOC BRASIL, Belo Horizonte/MG)

Semana da Fisioterapia (19:2021)

Anais da [...] / XIX Semana da Fisioterapia, 13-30 outubro 2021; coordenadores Davi Silva de Sousa, Israel Clemeson Moutinho Leite, Jennifer Maia Pessoa. - Triunfo, PE: Omnis Scientia, 2021.

98 p. ; il.

Formato: PDF

Requisitos de sistema: Adobe Acrobat Reader

Modo de acesso: World Wide Web

ISBN 978-65-88958-75-9

DOI 10.47094/978-65-88958-75-9

1. Fisioterapia - Brasil - Congressos. I. Sousa, Davi Silva de. II. Leite, Israel Clemeson Moutinho. III. Pessoa, Jennifer Maia.

CDD 615.82

Elaborado por Maurício Amormino Júnior - CRB6/2422

Editora Omnis Scientia

Triunfo - Pernambuco - Brasil

Telefone: +55 (87) 99656-3565

editoraomnisscientia.com.br

contato@editoraomnisscientia.com.br 


\section{PREFÁCIO}

A XIX SEMANA DA FISIOTERAPIA com o tema "Fisioterapia: fator essencial para saúde e bem-estar na atualidade", foi promovida pelo Centro Acadêmico de Fisioterapia (CAFISIO) da Universidade do Estado do Pará (UEPA) - Campus XII, localizada na cidade de Santarém, estado do Pará. O evento foi realizado nos dias 13, 14, 15 e 16 de outubro de 2021, no formato híbrido, ou seja, algumas atividades foram realizadas de forma remota (online) e outras de maneira presencial (nas dependências da UEPA).

Em meio a pandemia da Covid-19, eventos deste caráter tiveram inúmeras limitações, uma delas foi o modo de realização que passou a ser restrita ou limitada quando organizada de forma presencial devido as altas taxas de propagação e contaminação do vírus em locais fechados. Tal situação se tornou uma barreira, porém, com resiliência conseguimos nos reinventar e pensar em soluções promissoras, que nos dessem a oportunidade de fazer uma Semana inclusiva, acessível e inesquecível.

Somado ao momento pandêmico vivenciado, a realização do evento no formato híbrido também surgiu da necessidade de expandi-lo para outras regiões, para que se ultrapasse as fronteiras geográficas e se fizesse presente na vida de estudantes, profissionais e pesquisadores de todo o Brasil, uma vez que a propagação do conhecimento, o fomento à produção científica, o compartilhamento e a integração do saber foram os grandes objetivos da XIX Semana da Fisioterapia. Com isso, o evento conseguiu ser palco de difusão do conhecimento em vários estados brasileiros como o Pará, Amazonas, Rio Grande do Sul, São Paulo e Bahia.

Foi um verdadeiro desafio para nós, organizadores, realizar um evento totalmente inovador, com um formato diferente, que teve atividades tanto onlines como presenciais, que incluíam apresentações de trabalhos, palestras e workshops, propiciando um debate amplo sobre a fascinante Fisioterapia em seus diversos aspectos.

A XIX Semana de Fisioterapia obteve a marca de mais de 150 inscritos, cerca de 50 submissões de resumos científicos, dos quais 20 trabalhos foram apresentados oralmente (10 de forma presencial e 10 apresentados online), com base nos dois editais publicados - um edital para acadêmicos e profissionais de Santarém e outro para a comunidade científica de outras cidades e estados. Ainda, o evento contou com a participação de 14 profissionais que abrilhantaram o evento compartilhando o saber referente as mais diversas temáticas que permeiam as especialidades da Fisioterapia, por meio de palestras e workshops.

Encerramos a edição de 2021 com muita felicidade e sensação de dever cumprido. Foram momentos enriquecedores, em que a troca de experiência nos encorajou a olhar além e a difundir o saber, afinal de contas, segundo a antiga e necessária frase: "O conhecimento é a única coisa que ninguém pode nos tirar". 


\section{SUMÁRIO}

A AUTONOMIA PROFISSIONAL DO FISIOTERAPEUTA NA PANDEMIA DA COVID-19.....11

A CAPACIDADE FUNCIONAL DE IDOSOS EM INSTITUIÇÕES DE LONGA PERMANÊNCIA: UMA REVISÃO INTEGRATIVA.

A EFICÁCIA DA FISIOTERAPIA OBSTÉTRICA E SUAS TÉCNICAS NO PREPARO PARA O PARTO: UMA REVISÃO DE LITERATURA.....

A EFICÁCIA DAS MODALIDADES FISIOTERAPÊUTICAS NA REDUÇÃO DA INSTABILIDADE ARTICULAR DO TORNOZELO.

A FISIOTERAPIA NA FUNCIONALIDADE DE PACIENTES PORTADORES DE HIV AFETADOS PELA NEUROTOXOPLASMOSE.

A IMPORTÂNCIA DA REABILITAÇÃO FISIOTERAPÊUTICA NA SÍNDROME DE GUILLAIN-BARRÉ - REVISÃO INTEGRATIVA DE LITERATURA.

A IMPORTÂNCIA DA TERAPIA MANUAL NA TENDINITE CALCÁRIA DO SUPRAESPINHAL: RELATO DE EXPERIÊNCIA.

ABORDAGENS FISIOTERAPEUTICAS EM CRIANÇAS COM TRANSTORNO DO ESPECTRO AUTISTA

ALTERAÇÕES POSTURAIS POR AGRAVAMENTO DAS DISFUNÇÕES DA ARTICULAÇÃO TEMPOROMANDIBULAR.

ANÁLISE DAS PRINCIPAIS ABORDAGENS FISIOTERAPEUTICAS UTILIZADAS NO MANEJO DA ARTRITE REUMATÓIDE.

ASPECTOS EPIDEMIOLÓGICOS E INCIDÊNCIA DO TRAUMATISMO INTRACRANIANO EM SANTARÉM-PARÁ NO PERÍODO DE UMA DÉCADA.

ATUAÇÃO DA FISIOTERAPIA NA PREVENÇÃO DE QUEDAS EM IDOSOS: REVISÃO INTEGRATIVA DE LITERATURA.

ATUAÇÃO E ABORDAGENS FISIOTERAPÊUTICAS EM PACIENTES QUEIMADOS. 34 ATUAÇÃO E ABORDAGENS FISIOTERAPÊUTICAS NO TRATAMENTO DA DOR DO MEMBRO FANTASMA.

ATUAÇÃO FISIOTERAPÊUTICA EM PACIENTE SUBMETIDO A ARTROPLASTIA DE GIRDLESTONE: RELATO DE EXPERIÊNCIA......

ATUAÇÃO FISIOTERAPÊUTICA NO PROCESSO DE REABILITAÇÃO DE PACIENTES ACOMETIDOS PELA ESCLEROSE MÚLTIPLA...... 
ATUAÇÃO FISIOTERAPÊUTICA NO TRATAMENTO DE QUADROS ÁLGICOS EM PESSOAS QUE SOBREVIVERAM AO CÂNCER

AVANÇOS DA FISIOTERAPIA MANUAL ORTOPÉDICA NO TRATAMENTO DE ALGIAS LOMBARES: REVISÃO INTEGRATIVA..........................................................................4

BENEFÍCIOS DA ABORDAGEM FISIOTERAPÊUTICA NA DISPAREUNIA..........................46

BENEFÍCIOS DOS TREINOS VOLTADOS À FUNCIONALIDADE DE IDOSOS: UMA REVISÃO DE LITERATURA.

DISTRIBUIÇÃO DE MOBILIDADE DE CRIANÇAS E JOVENS COM PARALISIA CEREBRAL ENTRE OS NÍVEIS DO SISTEMA DE CLASSIFICAÇÃO DA FUNÇÃO MOTORA GROSSA (GMFCS)......

DOSIMETRIADO GERADOR DEALTAFREQUENCIANOPROCESSO DEREPAROTECIDUAL DE FERIDAS CUTANAES: ESTUDO EXPERIMENTAL.

EFEITO DO TREINAMENTO DO ASSOALHO PÉLVICO PARA REDUÇÃO DA INCONTINÊN-

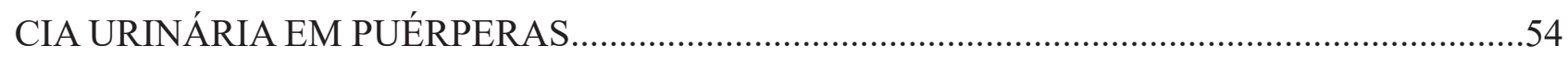

EFEITOS DA FISIOTERAPIA NAS LESÕES DE JOELHO EM ATLETAS................................56

EFEITOS DO TRATAMENTO COM REALIDADE VIRTUAL EM PACIENTES COM DOENÇA DE PARKINSON. .58

EFEITOS DO ULTRASSOM TERAPÊUTICO APLICADO EM PACIENTES COM TENDINITE CALCÁRIA DO SUPRAESPINHAL.

EFICÁCIA DA MEDITAÇÃO PARA A REDUÇÃO DA ANSIEDADE NO CONTEXTO DE ISOLAMENTO SOCIAL DECORRENTE DA PANDEMIA POR COVID-19.

EQUOTERAPIA COMO FERRAMENTA DE REABILITAÇÃO NA PARALISIA CEREBRAL...64 FISIOTERAPIA NA REABILITAÇÃO DE DOENÇAS OSTEOMIOARTICULARES RELACIONADO AO TRABALHO (DORT): REVISÃO INTEGRATIVA.

HIDROTERAPIA NO TRATAMENTO DE FIBROMIALGIA: RELATO DE EXPERIÊNCIA......68

O DESEMPENHO DOS OMBROS DOS PRATICANTES DE ESPORTES OVERHEAD.............70

O DIÁLOGO ENTRE IDOSOS E ESTUDANTES DE FISIOTERAPIA EM UMA UNIDADE MU-

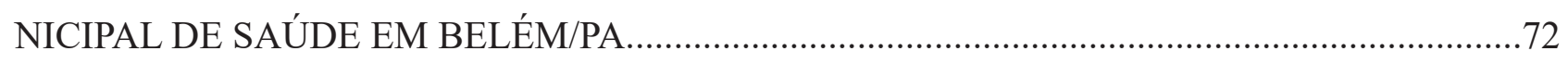

O TRABALHO DOCENTE E AS REPERCUSSÕES NA QUALIDADE DE VIDA DO PROFIS-

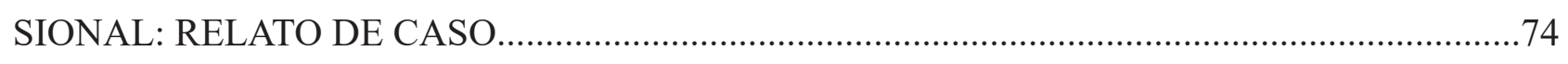

OS BENEFÍCIOS DO USO DO LED NO TRATAMENTO DA ACNE VULGAR.........................76

OS EFEITOS DA LASERTERAPIA DE BAIXA POTÊNCIA NA CICATRIZ DE ACNE..............78 
PANORAMA EPIDEMIOLOGICO DAS MALFORMAÇÕES CONGÊNITAS DO APARELHO OSTEOMUSCULAR NO ESTADO DO PARÁ, BRASIL.

PERFIL EPIDEMIOLÓGICO DOS PACIENTES ATENDIDOS NO AMBULATÓRIO DE FISIOTERAPIA DA UNIVERSIDADE DO ESTADO DO PARÁ, CAMPUS SANTARÉM.

PERSPECTIVAS E DESAFIOS DAS METODOLOGIAS ATIVAS NA FORMAÇÃO FISIOTERAPEUTICA: UM RELATO DE EXPERIÊNCIA DO INTERIOR DA AMAZÔNIA..... .84

PREVALÊNCIA E CARACTERÍSTICAS DA NEOPLASIA MALIGNA DO COLO UTERINO NA REGIÃO DO BAIXO AMAZONAS PARAENSE. .86

PROTOCOLO DE FISIOTERAPIA CARDIORRESPIRATÓRIAAPLICADO À PACIENTES PÓS-COVID 19: RELATO DE EXPERIÊNCIA. .88

REABILITAÇÃO DE PACIENTES COM SEQUELAS DA COVID-19 EM UMA ORGANIZAÇÃO NÃO GOVERNAMENTAL NO MUNICÍPIO DE ITAITUBA: RELATO DE EXPERIÊNCIA

REABILITAÇÃO FISIOTERAPÊUTICA EM ÍNDIVIDUOS JOVENS DIAGNOSTICADOS COM CÂNCER ÓSSEO. 92

REABILITAÇÃO RESPIRATÓRIA PÓS COVID-19: PRÁTICAS FISIOTERÁPICAS A PARTIR DO MÉTODO DE TELEREABILITAÇÃO.

RELEVÂNCIA DA INSERÇÃO EFETIVA DA FISIOTERAPIA NO PROGRAMA SAÚDE NA ESCOLA-PSE: REVISÃO DE LITERATURA. 
Izis Gabrielle Cordeiro Ribas ${ }^{1}$, Helen Regina Marques Carneiro² ${ }^{2}$ JulianaCorrea Cabral³ ; Vitória Gabrielle Teixeira Guimaraes ${ }^{4}$; Manoel Gionovaldo Freire Lourenço ${ }^{5}$

1,2,3,4 Discentes do curso de Fisioterapia, Universidade do Estado do Pará (UEPA). Belém, Pará, Brasil; ${ }^{5}$ Docente do curso de Fisioterapia, Doutor em ciências, Fisioterapeuta, Universidade do Estado do Pará (UEPA). Belém, Pará, Brasil.

INTRODUÇÃO: A fisioterapia é uma profissão de nível superior da área da saúde que atua em diferentes áreas e segmentos, no entanto, o fisioterapeuta era um profissional sem autonomia durante décadas. Após constantes lutas e embatespolíticos e sociais, a autonomia profissional foi conquistada e novas demandassurgiram. Este trabalho visa acrescentar novos aspectos acerca da discussão da autonomia profissional do fisioterapeuta diante dos novos desafios enfrentados durante a pandemia da COVID-19. OBJETIVO: identificar o exercício profissional do fisioterapeuta na linha de frente do combate ao novo corona vírus mediante sua autonomia nas unidades de terapia intensiva. METODOLOGIA: Trata-se de um estudo de levantamento bibliográfico a partir das bases de dados acadêmicos (SciELO e o google acadêmico), bem como de uma análise interpretativa do Código de Ética e Deontologia de Fisioterapia; no período de agosto e setembro de 2020. RESULTADOS E DISCUSSÃO: A partir do estudo foi possível encontrar 5 artigos, 01 resolução, 01 trabalho de conclusão de curso, 02 comunicados da ASSOBRAFIR. A análise interpretativa da resolução $n^{\circ}$ 424/2013 do COFFITO nos mostra através dos artigos $5^{\circ}$ e $9^{\circ}$, que o fisioterapeuta no exercício da profissão avalia a capacidade técnica e somente aceita atribuição ou assume o encargo mediante o desempenho seguro da sua atuação. Isso é reafirmado nos comunicados da ASSOBRAFIR os quais remetem a atribuição dos serviços do fisioterapeuta à disposição da comunidade em caso de guerra, catástrofe, epidemias ou crises sociais, sendo esses os deveres fundamentais do fisioterapeuta. CONCLUSÃO: A autonomia profissional do fisioterapeuta é assegurada pelo Código de Ética e Deontologia, de maneira que apesar das adversidades da Emergência de Saúde Pública de Importância Nacional, seus direitos e deveres foram adaptados para o melhor atendimento aos pacientes e contribuição para a saúde da comunidade nesse cenário de pandemia, sem ferir o direito do profissional ou do cidadão.

PALAVRAS-CHAVE: Fisioterapia; Autonomia Profissional; Infecções por corona vírus. 


\section{REFERÊNCIAS}

ASSOBRAFIR. Aspectos éticos e legais do atendimento de fisioterapia durante a pandemia da covid-19. 2020; Acesso em 23 set.2020.

FIGUEIREDO, Leandro Corrêa; GRATAO, Aline Cristina Martins; MARTINS,Emerson Fachin. Código de ética para fisioterapeutas e terapeutas ocupacionais revela conteúdos relacionados à autonomia do profissional. Fisioter. Pesqui., São Paulo, v. 20, n. 4, p. 394-400, Dec. 2013.

NOZAWA, Emilia et al. Perfil de fisioterapeutas brasileiros que atuam em unidades de terapia intensiva. Fisioter. Pesqui., São Paulo, v. 15, n. 2, p. 177-182, 2008.

NOZAWA, Emilia et al. Perfil de fisioterapeutas brasileiros que atuam em unidades de terapia intensiva. Fisioter. Pesqui., São Paulo, v. 15, n. 2, p. 177-182, 2008.

PIRES, Aparecida Cristina Chrispim; TELLES, Susana Cristina Lerosa. Fisioterapia respiratória na pandemia de Covid-19.Fisioter. Pesqui., São Paulo, v. 27, n. 2, p. 112, June 2020. 


\section{A CAPACIDADE FUNCIONAL DE IDOSOS EM INSTITUIÇÕES DE LONGA PERMA- NÊNCIA: UMA REVISÃO INTEGRATIVA}

\section{Dhéssy Emelly Travassos Gama ${ }^{1}$; Marcella Ayonan dos Santos Silva²; Paulo Henrique Ramos Pimentel $^{3}$.}

${ }^{1,2}$ Centro Universitário da Amazônia (UNAMA). Santarém, Pará, Brasil; ${ }^{3}$ Universidade do Estado do Pará (UEPA). Santarém, Pará, Brasil.

INTRODUÇÃO: A capacidade funcional é caracterizada como a habilidade do indivíduo em preservar as funções físicas e mentais primordiais, afim de manter sua independência, ela pode ser avaliada através: das Atividades Instrumentais de Vida Diária (AIVD) e Atividades Básicas de Vida Diária (ABVD). Devido ao aumento da população idosa, a procura por Instituições de Longa Permanência (ILPIS) cresce a cada dia, pois com o avançar da idade há o surgimento de várias alterações físicas e cognitivas, ocasionando consequências significativas na redução da qualidade de vida e incapacidade funcional. As ILPIs, são moradias especializadas que dão assistência aos idosos conforme as necessidades de seus residentes. OBJETIVO: Investigar o nível de capacidade funcional de idosos em instituições de longa permanência. METODOLOGIA: Trata-se de uma revisão de literatura do tipo integrativa, onde utilizou-se as bases de dados Scientific Electronic Library Online (Scielo) e PubMed, mediante os descritores: "Instituição de Longa Permanência para Idosos", "Classificação Internacional de Funcionalidade, Incapacidade e Saúde", "Fisioterapia" e seus correspondentes na língua inglesa: "Long-stay Institution for the Elderly"; "International Classification of Functioning"; "Disability and Health"; "Physiotherapy”. Foram incluídos artigos científicos caracterizados como ensaio clinico publicados nos últimos 10 anos (2012 - 2021) e referidos na língua portuguesa e inglesa que apresentem em seu conteúdo reação direta com o objetivo deste trabalho. RESULTADOS E DISCUSSÃO: Foram selecionados 5 artigos para análise. O nível de dependência funcional mostrou-se presente majoritariamente dentre os idosos institucionalizados, principalmente para as Atividades Instrumentais da Vida Diária, no que se refere as Atividades básicas de Vida diária as amostras apresentaram maior dependência nas tarefas de: Tomar banho e vestir-se, sendo que as doenças crônicas não transmissíveis podem ser um fator de risco para o declínio funcional, além disso, observou-se também a predominância do sexo feminino nas Instituições de Longa permanência. CONCLUSÃO: Em suma, a institucionalização pode ser um fator que contribuirá para o desenvolvimento de alterações na capacidade funcional dos idosos e assim acarretar maior dependência na realização das atividades de vida diária.

PALAVRAS-CHAVE: Instituição de Longa Permanência para Idosos; Classificação Internacional de Funcionalidade, Incapacidade e Saúde; Fisioterapia. 


\section{REFERÊNCIAS}

LEÃO RO, et al. Análise comparativa da capacidade funcional de idosos institucionalizados e não institucionalizados. FisiSenectus, v. 5, n. 1, p. 3-12, 2017.

LEITE AK, et al. Capacidade funcional do idoso institucionalizado avaliado pelo KATZ. Revista enfermagem atual in derme, v. 90, n. 21, p. 101-109, 2020.

REIS LAM, et al. Análise do grau de autonomia de residentes em uma Instituição de Longa Permanência. Revista Kairós-Gerontologia, v. 20, n. 23, p. 191-204, 2017.

SILVA CS, et al. Capacidade funcional de idosos em instituição de longa permanência. Id on Line Rev. Mult. Psic, v. 11, n. 38, 2017. 


\title{
A EFICÁCIA DA FISIOTERAPIA OBSTÉTRICA E SUAS TÉCNICAS NO PREPARO PARA O PARTO: UMA REVISÃO DE LITERATURA
}

\author{
Nathacha Karina Marreiros da Silva ${ }^{1}$; Indiara Alencar². \\ ${ }^{1}$ Centro Universitário da Amazônia (UNAMA). Santarém. Pará. Brasil; ${ }^{2}$ Universidade do Estado do \\ Pará (UEPA). Santarém. Pará. Brasil.
}

INTRODUÇÃO: O período gestacional é marcado por incertezas, medo e estimativas para a mulher por não se sentir preparada para a chegada do seu filho, e é durante o período da gravidez que o corpo da mulher sofre diversas alterações fisiológicas funcionais e estruturais. Na anatomia da pelve pode acarretar redução de força muscular do assoalho pélvico (AP), no qual forma a porção inferior da cavidade abdominal e pelve. O AP tem a capacidade de suportar cargas sendo responsável por suporte dos órgãos abdominais e pélvicos, manutenção da continência urinária e fecal, aumento da pressão intra-abdominal, na respiração e estabilização do tronco. Devido à sobrecarga nessa musculatura durante o período gestacional pode ocorrer incontinência urinária, laceração do períneo, dispareunia e disfunção sexual. No entanto a fisioterapia busca intervenções que possam evitar que tais fatos ocorram, através de avaliações e acompanhamento das alterações físicas, buscando promover bem estar a parturiente. OBJETIVO: O estudo buscou por meio do levantamento de literaturas analisar a eficácia das técnicas utilizadas pela fisioterapia obstétrica no preparo para o parto. METODOLOGIA: trata-se de uma revisão bibliográfica do tipo integrativa, realizado no ano de 2021, tendo como critério a busca nas bases de dados LILACS, Google acadêmico, PubMed e Scielo, com os termos "Delivery obstetric", "physiotherapy" e "Labor presentation". Foram incluídos nesse trabalho artigos publicados entre 2013 e 2021, na língua inglesa e portuguesa. RESULTADOS E DISCUSSÃO: Os estudos encontrados ressaltam que a fisioterapia obstétrica no trabalho de parto se faz de suma importância, visto que as técnicas utilizadas apresentaram diminuição do risco de incontinência urinaria episiotomia, laceração e dor, tendo como métodos aplicados, a mobilidade pélvica em pé ou na bola suíça, agachamento, coordenação diafragmática, liberação miofascial na região lombo-sacro, treinamento muscular do assoalho pélvico e o uso do dispositivo Epi-no, proporcionando as parturientes um parto mais humanizado. CONCLUSÃO: conclui-se que a fisioterapia pode auxiliar no período gestacional e na prevenção de traumas físicos que podem vim a acometer as parturientes, promovendo assim um bem estar as mulheres. No entanto sugere-se maiores estudos sobre o tema, visto que poucos trabalhos voltados ao tema foram encontrados.

PALAVRAS-CHAVE: Parto obstétrico; Fisioterapia; Trabalho de parto. 


\section{REFERÊNCIAS}

LIMA, E. G. de S; PISCO, D. D.; OLIVEIRA, C.; BATISTA, P. A.; FRANCISCO, R. P. V.; TANAKA, C. Intervenções fisioterapêuticas para os músculos do assoalho pélvico no preparo para o parto: revisão da literatura e proposta de manual de orientação. Fisioterapia Brasil. v. 22 n. 2, 2021.

Disponível em: https://convergenceseditorial.com.br/index.php/fisioterapiabrasil/article/view/2882. Acesso em: 08 de out. 2021.

NUNES, G. da S.; SOUZA, P. C. de; VIAL, D. de S. Recursos Fisioterapêuticos para o alívio da dor no trabalho de parto. REVISTA FAIPE, [S.1.], v. 5, n. 1, p. 90-99, jul. 2017. ISSN 2179-9660. Disponível em: <https://www.revistafaipe.com.br/index.php/RFAIPE/article/view/51>. Acesso em: 08 out. 2021.

SANTOS, E. R. S.; OLIVEIRA, C. Influência da Cinesioterapia na fase ativa do trabalho de parto no centro de pré-parto, parto e pós-parto do Instituto da Mulher dona Lindu. Faculdade Ávila. 2014. Disponível em: https://portalbiocursos.com.br/ohs/data/docs/35/10_Infl._da_cinesio_na_fase_ ativa_do_trab.de_parto_no_centro_de_prY-parto_parto_e_pYs-parto_do_Inst._Mulher_Dona_Lindu.pdf. Acesso em: 08 de out. 2021. 


\title{
A EFICÁCIA DAS MODALIDADES FISIOTERAPÊUTICAS NA REDUÇÃO DA INSTABI- LIDADE ARTICULAR DO TORNOZELO
}

\author{
Sandro Júnio Assunção Amazonas; Davi Silva de Sousa²; Lenise Ascenção Silva Nunes³; \\ Mayara Renata Lima Mota ${ }^{4}$. \\ 1,2,3,4 Universidade do Estado do Pará (UEPA). Santarém, Pará, Brasil
}

INTRODUÇÃO: A entorse na articulação do tornozelo é uma das lesões musculoesqueléticas agudas mais recorrente, sendo frequente em atletas profissionais e amadores. Um programa de reabilitação adequado é de fundamental importância para a recuperação precoce da lesão, o retorno à função normal e melhor estabilidade na articulação. OBJETIVO: Analisar a eficácia das modalidades fisioterapêuticas na redução da instabilidade articular do tornozelo. METODOLOGIA: Trata-se de um estudo retrospectivo baseado na literatura através de consulta na base de dados Biblioteca Virtual em Saúde (BVS). Realizou-se um recorte temporal de 2016 a 2021. As palavras-chave utilizadas foram Fisioterapia, Instabilidade Articular e Articulação do Tornozelo. Os critérios de inclusão referem-se a trabalhos que constem na plataforma escolhida, que estejam dentro do recorte temporal, que foram escritos na língua portuguesa, espanhola ou inglesa e que sejam ensaios clínicos randomizados (ECR). Como critérios de exclusão estão os trabalhos que não estejam disponíveis completos gratuitamente e que não abordem a eficácia das modalidades fisioterapêuticas na redução da instabilidade articular do tornozelo. RESULTADOS E DISCUSSÃO: Na plataforma BVS, ao colocar as palavras-chaves foram encontradas 83 publicações, com o recorte temporal restaram 36 trabalhos, sendo excluído 01 por não estar disponível gratuitamente e 13 por não serem ECR, e mais 13 após a leitura de títulos restando ao total 09 artigos. Nos estudos, foram realizadas atividades para avaliar o equilíbrio dos participantes, verificou-se que a instabilidade articular de tornozelo possui relação com alterações proprioceptivas, além de ocasionar a redução da amplitude de movimento (ADM) dessa articulação. Utilizou-se como proposta de intervenção: a mobilização articular, alongamentos e exercícios de equilíbrio. Após a implementação dessas técnicas notou-se um aumento na ADM, analgesia e melhor desempenho nos exercícios de equilíbrio. Entretanto tais melhoras foram temporárias, não havendo benefício substancial à longo prazo de qualquer uma das intervenções. CONCLUSÃO: Ressaltamos a necessidade de realização de novos estudos com maior abordagem ao tema referido, para que consequentemente, possamos enriquecer o conhecimento sobre as modalidades fisioterapêuticas que podem ser empregadas para a construção de uma prática baseada em evidência de forma segura, adequada e eficaz.

PALAVRAS-CHAVE: Fisioterapia; Instabilidade Articular; Articulação do Tornozelo. 


\section{REFERÊNCIAS}

FELAND, J. B. et al. Whole-body vibration and stretching enhances dorsiflexion range of motion in individuals with chronic ankle instability. Physical Therapy in Sport, v. 44, p. 1-7, 2020.

MCKEON, Patrick O.; WIKSTROM, Erik A. The effect of sensory-targeted ankle rehabilitation strategies on single-leg center of pressure elements in those with chronic ankle instability: A randomized clinical trial. Journal of science and medicine in sport, v. 22, n. 3, p. 288-293, 2019.

POWDEN, Cameron J. et al. Response shift after a 4-week multimodal intervention for chronic ankle instability. Journal of athletic training, v. 54, n. 4, p. 397-402, 2019.

SHIN, Ho-Jin et al. Manipulative Therapy Plus Ankle Therapeutic Exercises for Adolescent Baseball Players with Chronic Ankle Instability: A Single-Blinded Randomized Controlled Trial. International Journal of Environmental Research and Public Health, v. 17, n. 14, p. 4997, 2020.

VIEIRA, Sandro Emílio; DA SILVA REZENDE, Matheus. Tratamento fisioterapêutico para instabilidade articular nas entorses de tornozelo. Scire Salutis, v. 10, n. 2, p. 9-17, 2020. 


\title{
A FISIOTERAPIA NA FUNCIONALIDADE DE PACIENTES PORTADORES DE HIV AFE- TADOS PELA NEUROTOXOPLASMOSE
}

\author{
Isabelle de Oliveira Costa ${ }^{1}$; Rafael Moab Sousa dos Santos ${ }^{2}$. \\ ${ }^{1,2}$ Hospital Regional do Tapajós (HRT). Itaituba, Pará, Brasil.
}

INTRODUÇÃO: A Neurotoxoplasmose é uma das principais doenças oportunistas em indivíduos portadores do Vírus da Imunodeficiência Humana (HIV), sendo causada pela infecção latente do Toxoplasma gondii e ocorre quando os níveis de linfócitos TCD4 encontram-se abaixo de 200 células/ $\mathrm{mm}^{33}$. Estima-se que esteja presente entre $5 \%$ a $15 \%$ dos casos de pacientes vivendo com o HIV. A doença caracteriza-se como a causa mais comum de lesões cerebrais expansivas, com determinadas sequelas neurológicas, gerando efeitos negativos à funcionalidade, constituindo-se uma importante causa de morbidade e mortalidade, além de comprometer a realização das Atividades da Vida Diária (AVDs). O quadro clínico varia segundo a topografia e a quantidade de lesões cerebrais, entretanto, podem ocorrer episódios de febre, cefaleia intensa, convulsões, tremores, alteração do nível de consciência, alucinações, distúrbios da fala e desordens de movimento. OBJETIVO: Este trabalho tem como objetivo demonstrar, por meio de revisão integrativa da literatura, as implicações da fisioterapia na funcionalidade de pacientes portadores de HIV que adquiriram Neurotoxoplasmose. METODOLOGIA: Foi realizada uma busca de artigos publicados nos últimos 5 anos, nas bases de dados Scielo e Lilacs, nos idiomas inglês e português, com os descritores: Fisioterapia, Funcionalidade, HIV, Neurotoxoplasmose e AVDs. RESULTADOS E DISCUSSÃO: Foram encontrados 10 artigos que se enquadraram nos critérios de inclusão na pesquisa. Devido ao acometimento dos gânglios basais, algumas desordens motoras podem ser observadas, dentre elas, destaca-se a hemiparesia. Também está presente o comprometimento do equilíbrio postural, podendo prejudicar a deambulação em casos mais agravados. Além disso, a redução da capacidade funcional implica no maior risco de sofrer quedas. Constatou-se que a fisioterapia atua na melhora do equilíbrio estático e dinâmico, além do auxílio no ganho da mobilidade e na realização de AVDs, aumentando a funcionalidade, o grau de independência e a participação social dos indivíduos. CONCLUSÃO: Dessa forma, apesar da escassez de estudos sobre a atuação da fisioterapia em pacientes com HIV acometidos pela Neurotoxoplasmose, faz-se necessário entender a importância da efetivação do tratamento fisioterapêutico na funcionalidade e consequente melhora na qualidade de vida desses pacientes.

PALAVRAS-CHAVE: Neurotoxoplasmose; HIV; Fisioterapia. 


\section{REFERÊNCIAS}

AMORIM, Tamaiara Barbosa do; SANTANA, Elis Passos; SANTOS, Kionna Oliveira Bernardes. Perfil Sintomatológico de indivíduos com HIV/AIDS em um setor de fisioterapia. Fisioter. Mov. (Online) ; 30(1): 107-114, Jan.-Mar. 2017.

Araujo, Isabella Ribeiro et al. Déficits motores e preditores de perda de mobilidade ao final da internação em indivíduos com neurotoxoplasmose. Fisioterapia e Pesquisa [online]. 2019, v. 26, n. 4 [Acessado 28 Fevereiro 2021] , pp. 360-365. Disponível em: <https://doi.org/10.1590/18092950/18017926042019>.

BRASIL. Ministério da Saúde. Secretaria de Vigilância em Saúde. Departamento de IST, HIV/AIDS e Hepatites Virais. Protocoloclínico e diretrizes terapêuticas para manejo da infecção pelo HIV em adultos. Brasília, DF; 2017. 


\title{
A IMPORTÂNCIA DA REABILITAÇÃO FISIOTERAPÊUTICA NA SÍNDROME DE GUILLAIN-BARRÉ - REVISÃO INTEGRATIVA DE LITERATURA
}

\author{
André Salin de Menezes Nunes ${ }^{1}$; Ariely Aragão de Sousa ${ }^{2}$; Amanda Eduarda da Costa Sousa ${ }^{3}$; \\ Gleyce Helen dos Santos Carvalho ${ }^{4}$; Meriam de Nazaré Marques Ferreira ${ }^{5}$. \\ 1,2,3,4,5 Universidade do Estado do Pará (UEPA). Tucuruí, Pará, Brasil.
}

INTRODUÇÃO: A Síndrome de Guillain-Barré (SGB) é uma doença autoimune que atinge a bainha de mielina dos nervos periféricos, provocando alterações motoras e sensoriais no indivíduo, podendo ser desencadeada por origem bacteriana ou viral. Os principais sintomas é a fraqueza progressiva e a perda de sensações, impactando na coordenação motora e funcional. Nesse sentido, por ser uma patologia progressiva e com sequelas severas, a atuação do fisioterapeuta desde o diagnóstico se faz necessária. OBJETIVO: Evidenciar a importância da atuação da fisioterapia reabilitadora em pacientes portadores da SGB. METODOLOGIA: Refere-se a uma revisão integrativa de literatura, executada em setembro de 2021, utilizando as bases de dados Google Academic, Scielo, PUBMED, aplicando os descritores "Fisioterapia, "Síndrome de Guillain-Barré" e "Reabilitação", sendo ministrados artigos publicados entre 2015 e 2019. RESULTADOS E DISCUSSÃO: A princípio, dentre os 13 artigos encontrados, apenas 5 foram ultilizados para revisão. Observou-se que todos os autores alegam a importância da atuação fisioterapêutica desde a prevenção de agravos até à reabilitação, frisando a eficácia na recuperação funcional do paciente, proporcionando assim uma melhora na qualidade de vida. Deve-se considerar que independente da condição onde paciente se encontra, ainda que o diagnóstico atrase, o tratamento deve estar presente mesmo em casos na fase aguda. Um dos autores explana sobre a fisioterapia na reabilitação de pacientes com insuficiência respiratória, como primordial para evitar ao máximo a necessidade da ventilação mecânica invasiva, em virtude do eficaz resultado de treinamento muscular inspiratório. Os autores reforçam a validação de exercícios motores e neurofuncionais durante o tratamento, estabelecendo integralidade da atuação fisioterapêutica na equipe multidisciplinar, fazendo a diferença no quadro clínico do paciente. CONCLUSÃO: Diante do exposto, nota-se o quão fundamental é a fisioterapia para pacientes com o diagnóstico da SGB, tanto para a prevenção de sequelas futuras, quanto para a reabilitação da coordenação motora e funcional, restabelecimento a função muscular, possibilitando o retorno às atividades de vida diárias. Além disso, uma vez que pesquisas sobre essa temática ainda são reduzidas, logo é importante a continuidade de novos estudos que demostrem a importante inserção da fisioterapia no tratamento da SGB.

PALAVRAS-CHAVE: Fisioterapia; Síndrome de Guillain-Barré; Reabilitação. 


\section{REFERÊNCIAS}

ARAÚJO, Adriele Mascarenhas; et al. Treinamnto Muscular Inspiratório na Sindrome Guillain-Barré: Relato de Caso. Revista Pesquisa em Fisioterapia, 6v., nº 4, p. (448-454), nov., 2016.

ANTUNES, Mateus Dias; et. al. Efeito da Fisioterapia na Síndrome de Guillain-Barré. IX EPCC Encontro Internacional de Produção Científica UniCesumar, Matingá-Paraná, n.9, p. 4-6, ISBN 978-85-8084-996-7. nov. 2015.

CARVALHO, Fábio Luis Oliveira; et. al. Relação do Tratamento Fisioterapêutico Neurofuncional em Complicações Geradas pela Síndrome de Guillain-Barré e sua Relação com o Zika Vírus. Revista Saúde em Foco. Ed. no 11. 2019.

ROCHA, Amanda Pereira; et.al. Atuação da fisioterapia na reabilitação de pacientes com Síndrome de Guillain-Barré. Fisioterapia Brasil. São Paulo, 16 v., nº 6, p.778-787, set. 2017.

VASCONCELOS, Karem Katiúscia Melo. Importância da Fisioterapia na Reabilitação de Pacientes com a Síndrome de Guillain-Barré. 12 folhas. Trabalho de conclusão de curso. Faserra, Manaus, 2017. 


\title{
A IMPORTÂNCIA DA TERAPIA MANUAL NA TENDINITE CALCÁRIA DO SUPRAES- PINHAL: RELATO DE EXPERIÊNCIA
}

\author{
Thiago da Costa Alexandrino루 Mayara Renata Lima Mota ${ }^{2}$; John Henry de Oliveira Vale ${ }^{3 .}$ \\ ${ }^{1,2,3}$ Universidade do Estado do Pará (UEPA). Santarém, Pará, Brasil.
}

INTRODUÇÃO: A tendinite calcária do ombro é caracterizada como uma patologia autolimitante causando dor, limitação funcional e que, normalmente, acomete mulheres entre a quinta e sexta década de vida. Não possui etiologia conhecida, porém é evidenciado que dentre os músculos possíveis de ser acometidos, o supraespinhal apresenta maior proporção em comparação com o infraespinhal e o subescapular. Dentre os tratamentos para a tendinite calcária do supraespinhal, encontra-se o tratamento conservador e o cirúrgico, onde ambas necessitam de ação fisioterapêutica para alívio dos sintomas álgicos e da limitação de movimento, utilizando dentre os recursos a terapia manual. OBJETIVO: Relatar a importância da terapia manual nos atendimentos em paciente com lesão de tendinite calcária. METODOLOGIA: Os atendimentos foram realizados no ambulatório de fisioterapia da Universidade do Estado do Pará (UEPA) e ocorreram nos meses de Junho e Agosto de 2021, totalizando 15 atendimentos com duração de 50 minutos cada aproximadamente. RESULTADOS E DISCUSSÃO: Durante avaliação, paciente apresentava $74^{\circ}$ de flexão de ombro esquerdo, $55^{\circ}$ de abdução, $0^{\circ}$ de rotação lateral e com queixas álgicas do tipo parestesia no trajeto entre o ombro e o cotovelo. Os atendimentos iniciavam com a paciente em decúbito dorsal no leito e eram utilizadas técnicas da terapia manual como inibição, pompagem dos músculos da região cervical, tração cervical, além das mobilizações articulares para ganho da amplitude de movimento. Ao final dos atendimentos, foi realizada nova avaliação e verificada ausência das queixas álgicas, aumento de $32^{\circ}$ para flexão e de $12^{\circ}$ para abdução de ombro esquerdo, corroborando com os autores que afirmam que a maneira adequada de tratar uma desordem mecânica é utilizando-se de técnicas que tratem a mecânica daquele movimento. CONCLUSÃO: Conclui-se que a Terapia Manual é um recurso importante na reabilitação da tendinite calcária de supraespinhal e auxilia na melhora das queixas álgicas e limitações no membro acometido podendo restaurar a saúde física e a funcionalidade.

PALAVRAS-CHAVE: Terapia Manual; Ombro; Tendinite. 


\section{REFERÊNCIAS}

BUTLER, D.S. Mobilização do sistema nervoso. São Paulo: Manole, 2003.

MAGNUSSON, SP. Passive properties of human skeletal muscle during stretch maneuvers. A review. Scand J Med Sci Sports. 1998 Apr;8(2):65-77. doi: 10.1111/j.1600-0838.1998.tb00171.x. PMID: 9564710.

REZENDE, M.J. Estudo da eficácia da terapia manual no tratamento da tendinite calcária do músculo supra-espinhal. Pleiade. Jan/Jun, 2008. 


\title{
ABORDAGENS FISIOTERAPEUTICAS EM CRIANÇAS COM TRANSTORNO DO ES- PECTRO AUTISTA
}

\author{
Alex Ripardo Da Silva1; Aline Mesquita Azevedo²; Tafne Moraes Pereira ${ }^{3}$, Lucas Gabriel de \\ Araújo Marcião ${ }^{4}$, José Alexandre da Silva Júnior5. \\ 1,2,3,5 Universidade do Estado do Pará (UEPA). Santarém, Pará, Brasil; ${ }^{4}$ Centro Universitário da Ama- \\ zônia (UNAMA). Santarém, Pará, Brasil.
}

INTRODUÇÃO: O Transtorno do Espectro Autista (TEA) é uma condição geral para um grupo de desordens complexas do desenvolvimento do cérebro, antes, durante ou logo após o nascimento. É caracterizado pelo comprometimento em três áreas do desenvolvimento: interação social, comunicação e comportamento. A fisioterapia motora é de extrema importância no tratamento de tal comorbidade, interferindo positivamente no desenvolvimento neuropsicomotor, independência e melhora da qualidade de vida. OBJETIVO: Analisar a intervenção fisioterapêutica no Transtorno do Espectro Autista em crianças. METODOLOGIA: Trata-se de uma revisão da literatura. Utilizou-se as bases de dados BVS e Scielo, mediante os descritores: Fisioterapia, Transtorno do Espectro Autista e Criança. Foram incluídos trabalhos relacionados à atuação da fisioterapia no TEA em crianças, publicados entre 2016 e 2021, no idioma português. RESULTADOS E DISCUSSÃO: Dos 8 artigos encontrados foram incluídos 3 trabalhos para análise. Quando se fala em corpo, temse que pensar que ele é um organismo vivo, emocional e social. As experiências motoras da criança são decisivas na elaboração progressiva das estruturas que, aos poucos, dão origem às formas superiores de raciocínio, isto é, em cada fase do desenvolvimento, ela consegue uma determinada organização mental que lhe permite lidar com o ambiente. Cerca de 50\% das crianças com TEA apresentam hipotonia além de alterações comportamentais, atraso no desenvolvimento neuropsicomotor, dificuldade de fala e dificuldade de interação social, porém esse quadro pode ser amenizado através da fisioterapia. Todos os artigos citaram resultados positivos em relação à atuação da fisioterapia no TEA, que deve abordar as disfunções motoras, o ambiente físico e social em que a criança está inserida, incluindo os familiares que estão diretamente ligados a ela. Dois artigos destacam que a abordagem terapêutica deve ser feita de forma lúdica sendo atrativa e descontraída. Um deles também mostrou que as crianças classificadas com grau de autismo leve a moderado apresentaram melhores resultados que as crianças com grau mais grave. CONCLUSÃO: Conclui-se, portanto que a fisioterapia é muito importante na intervenção do TEA, principalmente na estimulação sensorial e motora, ajuda na independência e confiança e deve ser feita de forma global atuando na totalidade da criança como ser vivente.

PALAVRAS-CHAVE: Fisioterapia; Transtorno do Espectro Autista; Criança. 


\section{REFERÊNCIAS}

AZEVEDO, Anderson; GUSMÃO, Mayra. A importância da fisioterapia motora no acompanhamento de crianças autistas. Revista Eletrônica Atualiza Saúde. Salvador, v. 2, n. 2, p.76-83. 2016.

FERREIRA, Jackeline Tuan Costa, FERNANDA, Natália Mira; CRISTINA, Flávia Carbonero; Campos, Denise. Efeitos da fisioterapia em crianças autistas: estudo de séries de casos. Cad. Pós-Grad. Distúrb. Desenvolv., São Paulo, v. 16, n. 2, p. 24-32, dez. 2016.

PRATES, Amanda; BONIFÁCIO, Denise; MAGNANI, Maria; VICENTINI, Carolina; MUNIZ, Gabriela; MACHADO, Carla; ELIAS, Selmo. Os benefícios da fisioterapia na independência funcional em crianças com transtorno do espectro autista. Revista Unisalesiano Saúde. São Paulo, n.4, p.7886. 2019. 


\title{
ALTERAÇÕES POSTURAIS POR AGRAVAMENTO DAS DISFUNÇÕES DA ARTICULAÇÃO TEMPOROMANDIBULAR
}

\author{
Nicole Adriane Alves de Jesus ${ }^{1}$, Yaritsa Gabrielly da Silva Campos ${ }^{2}$, Sara Farias Oliveira ${ }^{3}$, Lo- \\ rena Maria Souza da Silva ${ }^{4}$ Elidiane Moreira Kono ${ }^{5}$ \\ 1,2,3,4,5Universidade do Estado do Pará (UEPA), Santarém, Pará, Brasil.
}

INTRODUÇÃO: A Disfunção Temporomandibular (DTM) é definida como um conjunto de desordens que acometem a articulação temporomandibular (ATM), os músculos mastigatórios e as estruturas anexas do sistema estomatognático. A ATM está diretamente relacionada às regiões cervical e escapular, por meio de um sistema neuromuscular comum, e a presença da disfunção pode alterar o equilíbrio corporal e, posteriormente, levar ao desequilíbrio muscular, coordenação motora prejudicada, fadiga muscular e sintomas de dor. Portanto, é proposto a influência da DTM sobre a postura corporal. OBJETIVO: Conhecer quais são as alterações posturais causadas pelo agravamento da DTM. METODOLOGIA: Trata-se de uma revisão da literatura, pesquisada nas plataformas PubMed, Scielo, Lilacs, PEdro e MEDline a partir dos descritores: Disfunção temporomandibular, Postura, Coluna vertebral e seus equivalentes em inglês, nos últimos 5 anos. Foram encontrados 33 artigos, dos quais apenas 12 apresentaram coerência com o objetivo do trabalho, seguindo critério de inclusão: artigos em inglês e português que contemplavam os descritores e que discorriam sobre alterações posturais relacionadas à DTM; e de exclusão: artigos que mencionavam efeitos de terapias sobre a disfunção temporomandibular, que não mencionavam alterações posturais e revisões de literatura. RESULTADOS E DISCUSSÃO: Em uma amostra foram analisados pacientes nos quais apresentaram DTM moderado $(21,8 \%)$, e severos $(0,9 \%)$ apresentando algum tipo de alteração postural relacionado a cabeça. Há relatos que no momento do quadro álgico a cabeça pode sofrer uma rotação ou inclinação, quanto a isso uma amostra evidenciou um alinhamento na angulação da cervical no momento em que a dor da DTM foi tratada, $88 \%$ das crianças apresentavam alterações nos ombros. Em outro estudo quanto ao sexo foi observado a DTM ser prevalente em mulheres, mas não foi relatado causar alterações no equilíbrio. A presença da DTM pode causar uma compensação dos músculos chamados contra apoios podendo levar a um encurtamento e tensão. CONCLUSÃO: Em suma, assim como os pacientes com DTM severo, os que apresentam DTM moderado também desenvolvem alteração postural. Além disso, as crianças com DTM apresentam alterações principalmente nos ombros.

PALAVRAS-CHAVE: Postura; Coluna vertebral; Articulação temporomandibular. 


\section{REFERÊNCIAS}

CHAVES, Paulo de Jesus et al. "Incidence of postural changes and temporomandibular disorders in students." Acta ortopedica brasileira vol. 25, n. 4, 2017.

DI GIACOMO, Paola et al. "Relationship between Cervical Spine and Skeletal Class II in Subjects with and without Temporomandibular Disorders." Pain research \& management, vol. 20184286796, 16 Oct. 2018.

KANG, Jeong-Hyun. "Effects on migraine, neck pain, and head and neck posture, of temporomandibular disorder treatment: Study of a retrospective cohort." Archives of oral biology, vol. 114-04718, 2020. 


\title{
ANÁLISE DAS PRINCIPAIS ABORDAGENS FISIOTERAPEUTICAS UTILIZADAS NO MANEJO DA ARTRITE REUMATÓIDE
}

\author{
Giovana Letícia Aguiar Fernandes'; Maria Nelcileny Leão Mota²; Israel Clemeson Moutinho \\ Leite $^{3}$; Vitória Maria Da Rold ${ }^{4}$; Mariana do Anjos Furtado de Sá5. \\ 1,2,3,4,5Universidade do Estado do Pará (UEPA). Santarém. Pará. Brasil.
}

INTRODUÇÃO: A artrite reumatóide (AR) é uma doença autoimune inflamatória crônica, de etiologia desconhecida, com prevalência em mulheres adultas. Caracteriza-se pela poliartrite periférica, o que resulta na destruição progressiva do sistema musculoesquelético. Devido a evolução da doença, o indivíduo afetado desenvolve incapacidades para exercer suas atividades, o que gera um impacto significativo tanto para a vida do paciente quanto para a sociedade. OBJETIVO: Realizar uma análise referente as principais abordagens fisioterapêuticas para o manejo da artrite reumatoide. METODOLOGIA: Trata-se de uma revisão integrativa da literatura, referente ao período de 2015 a setembro de 2021. Utilizou-se as bases de dados BVS e Google Acadêmico, empregando os seguintes descritores: Fisioterapia; Reabilitação; Artrite reumatoide; e equivalentes em inglês. Foram incluídos artigos publicados no idioma português ou inglês, ensaios clínicos randomizados, estudo de prevalência e relato de caso. Excluíram-se estudos de revisão e que não estivessem de acordo com o objetivo desta pesquisa. RESULTADOS E DISCUSSÃO: Dos 367 artigos encontrados, 11 estavam de acordo com o objetivo e critérios deste estudo. Após análise, verificou-se que as abordagens fisioterapêuticas utilizadas no manejo da artrite reumatóide foram benéficas, entre elas destacaram-se: exergaming ou "jogos ativos", terapia manual, programas de exercícios otimizados, mobilização neural, exercício aeróbico, laserterapia de baixa intensidade (LLLT), intervenções farmacológicas, balneoterapia e cinesioterapia. Um estudo experimental mostrou que a laserterapia de baixa intensidade não teve nenhuma eficácia no tratamento e reabilitação do paciente. Dessa forma, todos as outras abordagens apresentaram melhorias quanto ao tratamento e reabilitação do paciente, ocasionando bom funcionamento dos movimentos cinéticos funcionais, benefícios de reabilitação multidisciplinares, tratamento para algias, modulação imunológica, melhoria da capacidade aeróbica, equilíbrio, resistência e força nos mais velhos adultos, melhoria na qualidade do sono, melhora da qualidade de vida e dos transtornos depressivos, no equilíbrio e na força. CONCLUSÃO: Portanto, as abordagens fisioterapêuticas, como os exercícios em meio aquático, domiciliar e aeróbicos, a mobilização neural, o exergaming, fortalecimento e alongamento, planos cinesioterapêuticos, apresentaram diminuição da dor, melhora do equilíbrio, força, depressão, capacidade aeróbia, resistência, autoeficácia, aumento do trofismo muscular e qualidade de vida dos acometidos pela AR.

PALAVRAS-CHAVE: Fisioterapia; Reabilitação; Artrite reumatoide. 


\section{REFERÊNCIAS}

AMBROSINO, Pasquale et al. Exergaming as an additional tool in rehabilitation of young patients with rheumatoid arthritis: a pilot randomized controlled trial. Games for health journal, v. 9, n. 5, p. $368-375,2020$.

LANGE, Elvira et al. Effects of aerobic and resistance exercise in older adults with rheumatoid arthritis: a randomized controlled trial. Arthritis care \& research, v. 71, n. 1, p. 61-70, 2019.

LAU, Yan Nok et al. A brief report on the clinical trial on neural mobilization exercise for joint pain in patients with rheumatoid arthritis. Zeitschrift für Rheumatologie, v. 78, n. 5, p. 474-478, 2019.

VERHAGEN, Arianne P. et al. Balneotherapy (or spa therapy) for rheumatoid arthritis. Cochrane Database of Systematic Reviews, n. 4, 2015.

WILLIAMS, Mark A. et al. Strengthening And stretching for Rheumatoid Arthritis of the Hand (SARAH). A randomised controlled trial and economic evaluation. Health Technology Assessment (Winchester, England), v. 19, n. 19, p. 1-222, 2015. 


\title{
ASPECTOS EPIDEMIOLÓGICOS E INCIDÊNCIA DO TRAUMATISMO INTRACRANIA- NO EM SANTARÉM-PARÁ NO PERÍODO DE UMA DÉCADA
}

\author{
Israel Clemeson Moutinho Leite ${ }^{1}$; Lenise Ascenção Silva Nunes ${ }^{2}$; Yana Bernarde Sáz ${ }^{3}$ Daphne \\ Teodosio de Arruda ${ }^{4}$; José Alexandre da Silva Júnior ${ }^{5}$. \\ 1,2,3,4,5Universidade do Estado do Pará (UEPA). Santarém, Pará, Brasil.
}

INTRODUÇÃO: O Traumatismo intracraniano, no Brasil, representa a principal causa de morbimortalidade e seu número de ocorrências aumenta a cada ano. No período de 5 anos foram identificados 33.507 casos, apenas na região Norte do Brasil. Portanto, caracteriza-se como um problema de saúde pública, com impactos na qualidade de vida dos acometidos. OBJETIVO: Investigar os aspectos epidemiológicos do traumatismo intracraniano na cidade de Santarém-Pará no período de dez anos METODOLOGIA: Trata-se de um estudo epidemiológico descritivo com abordagem quantitativa, onde se utilizaram dados secundários através de consulta no Sistema de Informações Hospitalares do Sistema Único de Saúde (SIH-SUS). As variáveis selecionadas para análise da incidência do traumatismo intracraniano no município de Santarém, no estado do Pará, no período de 2010 a 2020 foram sexo, etnia, faixa etária, regime e caráter de atendimento, óbitos, taxa de mortalidade e valor total das internações. RESULTADOS E DISCUSSÃO: Em Santarém-Pará foram registrados 1.809 casos de traumatismo intracraniano, com média anual de 180,9. O ano de maior incidência foi 2015 com 19,2\% (349) dos acometimentos, ressaltando ainda que a partir desse ano houve decréscimo significativo, uma vez que em 2020 apenas 83 casos foram notificados. Além disso, a maioria dos pacientes eram homens, correspondendo a 1.270 (70,2\%) internações, havendo prevalência de pessoas pardas $(85,1 \%)$. A faixa etária com maior quantitativo de registros foi entre 20 a 49 anos $(48,6 \%)$, seguido de pessoas com até 19 anos (26,7\%), incluindo menores de 1 ano, crianças e adolescentes. Quanto ao regime de atendimento, 98,5\% das internações foram urgentes, com prevalência de atendimento no setor público (51,2\%), porém 48,2\% tiveram tal informação ignorada. Registraram-se 132 óbitos com uma taxa de mortalidade de 8,3, custando um valor total de $\mathrm{R} \$ 1.403 .570,19$ milhão por todas as internações. CONCLUSÃO: Conclui-se que há uma significativa incidência de casos de traumatismo intracraniano em Santarém-Pará, sendo necessário mais estudos para um maior grau de especificidade, tendo em vista possíveis falhas nos registros das internações e uma análise incompleta, mesmo havendo um perfil e características epidemiológicas já estabelecidas.

PALAVRAS-CHAVE: Traumatismo cranioencefálico; Epidemiologia; Internação hospitalar. 


\section{REFERÊNCIAS}

HOCHMAN, Bernardo et al. Desenhos de pesquisa. Acta Cirúrgica Brasileira, v. 20, p. 2-9, 2005.

JÚNIOR, Alexandre Otilio Pinto et al. ANÁLISE QUINQUENAL DAS INTERNAÇÕES DE PACIENTES COM TRAUMATISMO INTRACRANIANO NO BRASIL. ANÁLISE QUINQUENAL DAS INTERNAÇÕES DE PACIENTES COM TRAUMATISMO INTRACRANIANO NO BRASIL, p. 1-388-416. 2020.

Ministério da Saúde. Sistema de Informações Hospitalares do SUS (SIH/SUS). Acesso em: 23 set. 2021. Disponível em: http://tabnet.datasus.gov.br/cgi/deftohtm.exe?sih/cnv/nrpa.def 


\title{
ATUAÇÃO DA FISIOTERAPIA NA PREVENÇÃO DE QUEDAS EM IDOSOS: REVISÃO INTEGRATIVA DE LITERATURA
}

\author{
Amanda Eduarda da Costa Sousa ${ }^{1}$; Ariely Aragão de Sousa ${ }^{2}$; Emily Thaissa Louzada Mar- \\ ques $^{3}$; Rodrigo Wanzeler Pereira ${ }^{4}$; Soly Guedes de Oliveira ${ }^{5}$. \\ 1,2,3,4,5 Universidade do Estado do Pará (UEPA). Tucuruí, Pará, Brasil.
}

INTRODUÇÃO: Segundo a Organização Mundial da Saúde (OMS), até o período de 2050 o Brasil será um País com uma população triplicada de idosos em relação ao ano de 2019, sendo de $28 \%$ a $35 \%$ dessas pessoas com mais de 65 anos suscetíveis a quedas, essa percentagem aumenta com o passar do tempo e com o nível de fragilidade. O envelhecimento é uma causa natural e vem aumentando com o passar das décadas, com o avanço da medicina e melhoria da qualidade de vida. São considerados idosos pessoas com mais de 60 anos que, com o tempo, vão sofrendo alterações das suas capacidades neurobiológicas, funcionais e estruturais. Nesse contexto, a fisioterapia preventiva assume papel fundamental, atuando na estabilidade de coordenação motora, fortalecimento, funcionalidade, equilíbrio e entre outras, com objetivo de minimizar as consequências das alterações fisiológicas e patológicas naturais desse grupo. OBJETIVO: Identificar evidências atualizadas sobre a importância da fisioterapia preventiva na terceira idade, principalmente em relação as quedas. METODOLOGIA: Trata-se de uma revisão integrativa de literatura, realizada em setembro de 2021, onde foram utilizadas as bases de dados SciELO, Pubmed, google academic, utilizando os descritores "Fisioterapia", "Idosos", "Prevenção" e "Quedas". Foi definido critério de inclusão: artigos publicados entre 2016 e 2021 . RESULTADOS E DISCUSSÃO: Dos 10 artigos encontrados, foram incluídos 5 trabalhos específicos para análise, evidenciando-se uma relação preventiva da fisioterapia no cotidiano dos idosos como positivo. Denota-se que a maioria dos conteúdos analisados mostrou que os exercícios praticados ajudam na diminuição da incidência no risco de quedas, 2 estudos concluíram que ainda há dificuldades de planejamento de intervenções preventivas e poucos materiais sobre o tema abordado. CONCLUSÃO: Diante disso, nota-se que o profissional fisioterapeuta é de suma importância na atuação preventiva da saúde dos idosos, buscando de forma constante medidas que possam amenizar os fatores naturais do envelhecimento. Ademais, destaca-se a relevância de um programa constante de atividades praticas para este grupo, mas ainda há dificuldade de inserção desse profissional na atenção básica de saúde.

PALAVRAS-CHAVE: Fisioterapia; Idosos; Prevenção; 


\section{REFERÊNCIAS}

MERES, Madson Moreira. Afisioterapia na prevenção de quedas em idosos. 2018. Monografia (Graduação em Fisioterapia) Faculdade de Educação e Meio Ambiente. Rondônia, 2018.

OLIVEIRA, Hévelyn et al. Fisioterapia na prevenção de quedas em idosos: Revisão de literatura. Revista Interdisciplinar de Estudos Experimentais, v. 9, n. único, p. 43-47, 2017.

ORGANIZAÇÃO MUNDIAL DA SAÚDE (OMS). Relatório global da OMS sobre prevenção de quedas na velhice. Canadá, OMS, 2010.

REICHEL, Daniela. Atuação da fisioterapia na saúde do idoso na atenção básica: Uma revisão. 2019. Monigrafia (Pós-graduação em Administração) Universidade Federal do Rio Grande do Sul. Porto Alegre, 2019.

RODRIGUES, Ricardo; CERVAENUS, Mariana; A influencia da fisioterapia na prevenção de quedas no idoso - revisão bibliográfica. Universidade Fernando Pessooa, Porto, julho 2018. 


\title{
ATUAÇÃO E ABORDAGENS FISIOTERAPÊUTICAS EM PACIENTES QUEIMADOS
}

\author{
Tafne Moraes Pereiraㄹ ${ }^{1}$ Crícia Regina Figueira Araújo² ${ }^{2}$ Thiago Pereira Lemos ${ }^{3}$; Gabriel Ma- \\ theus Batista Brito ${ }^{4}$; Marina Silva Nicolau Taketomi ${ }^{5}$ \\ ${ }^{1,2,3,4,5}$ Universidade do Estado do Pará (UEPA). Santarém. Pará. Brasil.
}

INTRODUÇÃO: Queimaduras são lesões decorrentes de agentes capazes de produzir calor excessivo que danifica os tecidos corporais e acarreta na morte celular. Estima-se que no Brasil ocorram em torno de 1.000.000 de acidentes com queimaduras por ano e dependendo do grau pode ocorrer edema, quadros álgicos, inchaço, desprendimento de camadas da pele, estado de choque e óbito. OBJETIVO: Verificar a atuação e principais abordagens fisioterapêuticas utilizadas em pacientes queimados. METODOLOGIA: Trata-se de uma revisão da literatura através de consulta na base de dados Biblioteca Virtual da Saúde (BVS) e Google Acadêmico. Foram definidos como critérios de inclusão: artigos publicados no período de 2016-2021, no idioma português. Foram excluídos artigos duplicados e que não se adequavam ao tema. RESULTADOS E DISCUSSÃO: Inicialmente foram encontrados 28 estudos na plataforma BVS e 96 no Google acadêmico, após aplicação dos critérios de elegibilidade, 4 artigos foram selecionados para análise. Através dos artigos, observou-se que o fisioterapeuta detém de diversos métodos para atuar na reabilitação de pacientes queimados. Como principal intervenção na cicatrização, o laser auxilia no processo cicatricial e contribui na prevenção de complicações funcionais e estéticas. Ademais, quando aplicado em conjunto com luz intensa pulsada apresenta resultados favoráveis em casos de queimaduras extensas. Outro procedimento utilizado na cicatrização é a fototerapia que possui efeito anti-inflamatório reduzindo a duração do tratamento e tornando-o mais eficaz. Para preservação do movimento e amplitude do paciente, a cinesioterapia atua através de exercício ativo e passivo e alongamentos, dependendo do grau de lesão da queimadura. Para melhora da circulação sanguínea e maleabilidade tecidual, a massagem é indicada. Em casos mais graves, quando o paciente fica internado, o fisioterapeuta atua no posicionamento dos membros, adequando no leito, alternando de posições para prevenir úlceras de pressão, fibrose e rigidez muscular. CONCLUSÃO: Conclui-se que o fisioterapeuta é importante na assistência do paciente, aceleração e eficácia da cicatrização através da aplicação de recursos eletromorfoterapêuticos, da cinesioterapia e terapia manual, contribuindo também para prevenção de possíveis complicações.

PALAVRAS-CHAVE: Fisioterapia; Queimaduras; Cicatrização. 


\section{REFERÊNCIAS}

ARAÚJO, Raquel Rodrigues et al. Novas abordagens fisioterapêuticas na reabilitação de queimados em uma equipe multidisciplinar: relato de caso. 2016.

DO BONFIM, Laís Cisas et al. ATUAÇÃO FISIOTERAPÊUTICA NA REABILITAÇÃO DE PACIENTES QUEIMAdos. Anais da Mostra Acadêmica do Curso de Fisioterapia, v. 7, n. 1, p. 146-152, 2019

FERNANDES, Marília Isadora Silva. Atuação da fisioterapia dermatofuncional na reabilitação de pacientes queimados: uma revisão integrativa de literatura. Revista uningá, v. 56, n. 3, p. 176-186, 2019.

MONTEIRO, Adriana Chaves et al. BENEFÍCIOS DA FISIOTERAPIA EM PACIENTES QUEIMADOS NA UNIDADE DE TERAPIA INTENSIVA: Uma Revisão Integrativa. Revista CPAQV-Centro de Pesquisas Avançadas em Qualidade de Vida-CPAQV Journal, v. 12, n. 3, 2020. 


\title{
ATUAÇÃO E ABORDAGENS FISIOTERAPÊUTICAS NO TRATAMENTO DA DOR DO MEMBRO FANTASMA
}

\author{
Tafne Moraes Pereira ${ }^{1}$; Maria Beatriz Cardoso Magalhães Damasceno² ; Israel Clemeson \\ Moutinho Leite ${ }^{3}$; Marina Silva Nicolau Taketomi ${ }^{4}$. \\ 1,2,3,4 Universidade do Estado do Pará (UEPA). Santarém. Pará. Brasil.
}

INTRODUÇÃO: A dor do membro fantasma (DMF) é uma sensação álgica comumente percebida no membro ou extremidade amputada, caracterizando-se como quadro debilitante que afeta entre $50 \%$ a $85 \%$ dos acometidos após amputação. Além disso, interfere negativamente no bem-estar psicológico e nas atividades de vida diária desses indivíduos. OBJETIVO: Verificar como se dá a atuação da fisioterapia no tratamento da dor do membro fantasma e quais as principais abordagens. METODOLOGIA: Trata-se de um estudo retrospectivo baseado na literatura através de consulta na base de dados Biblioteca Virtual em Saúde (BVS) e PUBMED mediante uso das seguintes palavras-chave: Fisioterapia e Dor do Membro Fantasma, bem como seus correlatos em inglês. Foram definidos como critérios de inclusão: artigos publicados no período de 2016-2021, nos idiomas português e inglês e estudos do tipo ensaio clínico randomizado. Foram excluídos artigos duplicados nas bases, que não estavam disponíveis na íntegra gratuitamente e que não se enquadrassem à temática proposta. RESULTADOS E DISCUSSÃO: Inicialmente foram encontrados 9 estudos na plataforma BVS e 33 na PUBMED, após aplicação dos critérios de elegibilidade, 4 artigos foram selecionados para análise. O fisioterapeuta realiza procedimentos como: acupuntura, ultrassom e estimulação elétrica nervosa transcutânea. Porém, autores relataram que o nível de eficácia é baixo. Atualmente, a alternativa mais promissora do mercado é a terapia do espelho (TE). Em um estudo foi aplicado a TE nos pacientes durante 4 semanas, resultando na diminuição da gravidade da DMF. Em estudos comparativos, a terapia do espelho resultou em melhora da intensidade da dor, qualidade de vida e estado psicológico. Outros autores obtiveram os mesmos resultados comparando a terapia com o uso de imagens mentais. Entretanto, em um estudo realizou-se a comparação entre TE e exercícios sensomotores sem espelho durante quatro semanas e concluiu que a terapia do espelho tradicional foi menos eficaz. CONCLUSÃO: Portanto, o fisioterapeuta possui inúmeras abordagens empregadas durante sua atuação no processo de tratamento da DMF, mas alguns recursos são de baixa eficácia. No entanto, a terapia do espelho é um recurso promissor, pois diminui a gravidade da PLP, melhora a intensidade da dor e a qualidade de vida dos acometidos.

PALAVRAS-CHAVE: Fisioterapia; Dor; Membro fantasma. 


\section{REFERÊNCIAS}

KULUNKOGLU, Bahar Anaforoğlu; et al. Uma comparação dos efeitos da terapia do espelho e exercícios fantasmas na dor do membro fantasma. Jornal Turco de Ciências Médicas, Ancara, p. 101-109, 11 fev. 2019.

MALLIK, Amit Kumar; et al. Comparação dos benefícios relativos da terapia do espelho e imagens mentais na dor de membro fantasma em pacientes amputados em um centro de cuidados terciários. Arquivos de Pesquisa em Reabilitação e Tradução Clínica, Patna, 2020.

ROTHGANGEL, Andreas; et. Al. Terapia de espelho de realidade aumentada e tradicional para pacientes com dor crônica de membro fantasma (estudo PACT): resultados de um ensaio clínico randomizado cego simples-cego de três grupos. Reabilitação Clínica, Maastricht, p. 1591-1608, 08 jun. 2018

YILDIRIM, Meltem; et al. O efeito da terapia do espelho no tratamento da dor do membro fantasma. Istambul, p. 127-134, 18 jul. 2016. 


\title{
ATUAÇÃO FISIOTERAPÊUTICA EM PACIENTE SUBMETIDO A ARTROPLASTIA DE GIRDLESTONE: RELATO DE EXPERIÊNCIA
}

\author{
Thiago da Costa Alexandrino ${ }^{1}$, Mayara Renata Lima Mota ${ }^{2}$, John Henry de Oliveira Vale ${ }^{3}$ \\ 1,2,3Universidade do Estado Pará (UEPA). Santarém, Pará, Brasil.
}

INTRODUÇÃO: A artroplastia de ressecção de Girdlestone consiste em uma cirurgia de salvação onde é realizada a remoção da cabeça do fêmur do membro comprometido, mantendo o membro inferior conectado ao quadril somente através dos tecidos moles. É indicada em casos de infecções da prótese total de quadril e falhas cirúrgicas prévias, sem condições ósseas para realização de um procedimento cirúrgico que preserve a anatomia funcional articular. A fisioterapia surge com o papel importante na busca pela melhora funcional desses pacientes. OBJETIVO: Relatar a atuação do fisioterapeuta em paciente submetido a artroplastia de ressecção de Girdlestone. METODOLOGIA: Este relato é referente aos atendimentos efetuados no ambulatório de fisioterapia do Hospital Regional do Baixo Amazonas - Santarém (HRBA) com paciente submetido a procedimento cirúrgico de artroplastia de ressecção de Girdlestone no quadril direito. Os atendimentos aconteceram no mês de Setembro/2021, pelo período da manhã e totalizaram 12 atendimentos. Foram utilizados na conduta fisioterapêutica, recursos como a eletroterapia, a cinesioterapia ativa livre e resistida, treino de equilíbrio e o treino de marcha. RESULTADOS E DISCUSSÃO: Na avaliação, paciente apresentou-se em cadeira de rodas com diminuição de força muscular (grau 3) para os músculos dos membros inferiores. Os atendimentos iniciais consistiram na aplicação do FES sobre o quadríceps direito e cinesioterapia ativa livre sobre o leito. A partir do quarto atendimento, com paciente em sedestação beira leito era realizada cinesioterapia ativa livre e resistida, além do treino de equilíbrio em apoio unipodal. Do nono atendimento em diante, era realizada cinesioterapia resistida para todos os membros inferiores, treino de equilíbrio em apoio unipodal e treino de marcha com auxílio de muletas axilares. Ao final do último atendimento, foi identificada melhora na força muscular dos membros inferiores (Grau 4/5), nas transferências e na marcha com muletas com menor dificuldade e por maior distância.. CONCLUSÃO: A atuação fisioterapêtica é de grande valia no atendimento dos pacientes de artroplastia de ressecção de Girdlestone por ofertar a melhora do quadro geral do paciente, restaurar força muscular e proporcionar maior independência funcional.

PALAVRAS-CHAVE: Fisioterapia; Quadril; Artroplastia. 


\section{REFERÊNCIAS}

GRAUER JD, et. al. Resection arthroplasty of the hip. J Bone Joint Surg Am. 1989; 71: 669-78

TURIBIO et. al. Artroplastia de ressecção do quadril cirurgia de salvação. F Med. 1993

YAMAMOTO PA, et. al. Avaliação da função e qualidade de vida de pacientes submetidos a artro-

plastia de ressecção tipo Girdlestone. ACTA ORTOP BRAS 15 (4:214-217), São Paulo, 2007 


\title{
ATUAÇÃO FISIOTERAPÊUTICA NO PROCESSO DE REABILITAÇÃO DE PACIENTES ACOMETIDOS PELA ESCLEROSE MÚLTIPLA
}

\author{
Jennifer Maia Pessoa', Israel Clemeson Moutinho Leite²; Nicole Adriane Alves de Jesus ${ }^{3}$; Ju- \\ ciele Rodrigues de Aguiar ${ }^{4}$; Richelma de Fátima de Miranda Barbosa 5 . \\ 1,2,3,4 Universidade do Estado do Pará (UEPA). Santarém, Pará, Brasil. ${ }^{5}$ Universidade da Amazônia, \\ UNAMA, Brasil.
}

INTRODUÇÃO: A esclerose múltipla é uma doença neurológica, crônica e autoimune, que afeta a substância branca do sistema nervoso gerando lesões cerebrais e medulares, no qual a fisioterapia é um dos tratamentos utilizados que atua principalmente na fase aguda da doença. OBJETIVO: Realizar uma revisão integrativa da literatura referente a atuação fisioterapêutica na reabilitação de pacientes acometidos pela esclerose múltipla. METODOLOGIA: Trata-se de uma revisão integrativa da literatura, com recorte temporal de 2015 a setembro de 2021. Utilizou-se a Biblioteca Virtual em Saúde, por meio dos descritores: Fisioterapia, Reabilitação, Esclerose múltipla, Physical Therapy, Rehabilitation, Multiple Sclerosis. Foram incluídos artigos publicados nos idiomas portugueses ou inglês, ensaios clínicos controlados, estudos observacionais, de prevalência e estudos de caso. Excluíram-se qualquer tipo de revisão, que não possuem texto completo gratuito e que não estivessem de acordo com o objetivo geral do presente estudo. RESULTADOS E DISCUSSÃO: Após aplicação dos critérios de inclusão e exclusão destacaram-se três artigos. O primeiro estudo desenvolveu exercícios com o intuito de ativação do núcleo muscular através de estimulação sensorial, coordenação, dupla-tarefa, propriocepção, treino de grandes grupos musculares em ortostase, controle postural e treino de equilíbrio utilizando atividades em grupos, intervenção GroupCoreDIST, obtendo resultados positivos na ativação muscular do tronco, caminhada e equilíbrio. Somando a isso, outro estudo relacionou a realidade virtual à fisioterapia, interferindo positivamente no ganho de equilíbrio, confirmadas através de avaliação de posturografia computadorizada de paciente com EM influenciando diretamente na diminuição de insegurança dos pacientes em relação as quedas. Ademais, outro estudo destacou a positividade da ortostase - durante trinta minutos, três vezes na semana - utilizando estrutura de pé Oswestry de madeira durante 20 semanas, o qual agiu positivamente nas funções motoras. CONCLUSÃO: Portanto, nota-se a importância e a relevância do tratamento fisioterapêutico em paciente com EM para ter uma melhor qualidade de vida, diminuição de riscos de quedas e inseguranças que podem causar outros comprometimentos ao paciente, tendo em vista uma gama de protocolos que venham a ser utilizados para ganho de equilíbrio e melhora na função motora.

PALAVRAS-CHAVE: Fisioterapia; Reabilitação; Esclerose Múltipla. 


\section{REFERÊNCIAS}

ARNTZEN, Ellen; STRAUME, Bjorn; ODEH, Francis; FEYS, Peter; NORMANN, Britt. Groupbased, individualized, comprehensive core stability and balance intervention provides immediate and long-term improvements in walking in individuals with multiple sclerosis: A randomized controlled trial. Wiley. https://doi.org/10.1002/pri.1798. Maio. 2019.

DE SOUZA, Stéfany Vitor Ferreira; RIESCO, Thaís Bandeira. A contribuição da fisioterapia para pacientes com esclerose múltipla. AMAZÔNIA: SCIENCE \& HEALTH. v. 9, n. 3, p. 21-28, 2021.

FREEMAN, Jennifer et al. Assessment of a home-based standing frame programme in people with progressive multiple sclerosis (SUMS): a pragmatic, multi-centre, randomised, controlled trial and cost-effectiveness analysis. The Lancet Neurology, v. 18, n. 8, p. 736-747, 2019.

KALRON, Alon; FONKATZ, Ilia; FRID, Lior; BARANSI, Hani; ACHIRON, Anat. The effect of balance training on postural control in people with multiple sclerosis using the CAREN virtual reality system: a pilot randomized controlled trial. Journal of NeuroEngineering and Rehabilitation. v.13, p.2-10. 2016. 


\title{
ATUAÇÃO FISIOTERAPÊUTICA NO TRATAMENTO DE QUADROS ÁLGICOS EM PESSOAS QUE SOBREVIVERAM AO CÂNCER
}

\author{
João Gustavo Nascimento da Silva ${ }^{1}$; Maria Nelcileny Leão Mota²; Luandra Dias da Silva ${ }^{3}$; \\ Giovana Letícia Aguiar Fernandes ${ }^{4}$; José Alexandre da Silva Júnior 5 . \\ 1,2,3,4,5 Universidade do Estado do Pará (UEPA). Santarém. Pará. Brasil.
}

INTRODUÇÃO: Câncer é um termo que abrange mais de 100 diferentes tipos de doenças malignas que têm em comum o crescimento desordenado de células. Dividindo-se rapidamente, estas células tendem a ser muito agressivas e incontroláveis. O estado de cronicidade dos sobreviventes do câncer sugere uma necessidade crescente de reabilitação. Dessa forma, técnicas fisioterapêuticas aplicadas para o tratamento de quadros álgicos, têm sido de suma importância, trazendo benefícios para os pacientes e melhor qualidade de vida. OBJETIVO: Investigar a atuação fisioterapêutica referente ao tratamento da dor em pacientes sobreviventes do câncer. METODOLOGIA: Trata-se de uma revisão integrativa da literatura, referente ao período de 2015 a setembro de 2021 . Utilizou-se as bases de dados SCIELO, BVS e PUBMED, empregando os seguintes descritores: fisioterapia; dor de câncer; sobreviventes do câncer; e equivalentes em inglês. Foram incluídos estudos publicados no idioma inglês ou português, ensaios clínicos e estudos randomizados. Excluíram-se estudos que fossem qualquer tipo de revisão e que não estivessem de acordo com o objetivo de estudo. RESULTADOS E DISCUSSÃO: Foram encontrados 203 artigos, onde 12 foram incluídos neste estudo. Após análise dos artigos, verificou-se que em uma intervenção com ioga somático e meditação, houve melhoras em pacientes acometidos por neuropatia periférica induzida pela quimioterapia. Além disso, outro estudo relacionado a pacientes que foram curados do câncer de mama, porém com algias miofasciais crônicas, revelou que a cinesioterapia, em conjunto com a compressão isquêmica, ajuda grandemente no alívio dessas dores. Já no que tange o tratamento de idosos oncológicos com a utilização de técnicas manuais de osteopatia, uma pesquisa chegou às seguintes conclusões: foram percebidas evoluções consideráveis no alívio de dores, mas não na qualidade de vida de pacientes hospitalizados. Ademais, outro estudo mostrou que o tratamento miofascial em mulheres que sobreviveram ao câncer de mama, apresenta benefícios físicos ligados à movimentação e à funcionalidade do ombro. CONCLUSÃO: Nota-se a importância da fisioterapia na reabilitação de pacientes sobreviventes de um câncer. Portanto, as intervenções com ioga somático e meditação, cinesioterapia juntamente com a compressão isquêmica, e técnicas manuais de osteopatia são as melhores alternativas, com resultados satisfatórios, para o alívio das algias oncológicas.

PALAVRAS-CHAVE: Fisioterapia; Dor do câncer; Sobreviventes do câncer. 


\section{REFERÊNCIAS}

ARIENTI, Chiara et al. Osteopathic manipulative treatment effect on pain relief and quality of life in oncology geriatric patients: a nonrandomized controlled clinical trial. Integrative cancer therapies, v. 17, n. 4, p. 1163-1171, 2018.

GALIANO-CASTILLO, Noelia et al. Telehealth system: A randomized controlled trial evaluating the impact of an internet-based exercise intervention on quality of life, pain, muscle strength, and fatigue in breast cancer survivors. Cancer, v. 122, n. 20, p. 3166-3174, 2016.

GALANTINO, Mary Lou et al. Impact of somatic yoga and meditation on fall risk, function, and quality of life for chemotherapy-induced peripheral neuropathy syndrome in cancer survivors. Integrative cancer therapies, v. 18, p. 1534735419850627, 2019.

PAULO, Thais RS et al. The impact of an exercise program on quality of life in older breast cancer survivors undergoing aromatase inhibitor therapy: A randomized controlled trial. Health and quality of life outcomes, v. 17, n. 1, p. 1-12, 2019.

RANGON, Flávia Belavenuto et al. Ischemic compression and kinesiotherapy on chronic myofascial pain in breast cancer survivors. Journal of bodywork and movement therapies, v. 22, n. 1, p. 69$75,2018$. 


\title{
AVANÇOS DA FISIOTERAPIA MANUAL ORTOPÉDICA NO TRATAMENTO DE ALGIAS LOMBARES: REVISÃO INTEGRATIVA
}

\author{
Juliana Nascimento da Silva'; José Alexandre da Silva Júnior²․ \\ 1,2Universidade do Estado do Pará (UEPA). Santarém, Pará, Brasil.
}

INTRODUÇÃO: As algias que acometem a região lombar são sintomas crônicos recorrentes, capazes de comprometer a qualidade de vida do paciente, afetando-o no âmbito físico, emocional, funcional e social. Além disso, a dor lombar (DL) é uma causa recorrente de incapacidade, tendo prevalência de 60-85\% entre os indivíduos - independente de faixa etária ou sexo. Assim, surgi a discussão sobre a atuação da fisioterapia manual ortopédica no manejo da DL, enfatizando os avanços da terapêutica. OBJETIVO: Analisar os avanços da fisioterapia manual ortopédica no tratamento de pacientes portadores de algias lombares. METODOLOGIA: A coleta bibliográfica, foi realizada em artigos dos anos 2020-2021, nas bases de dados PubMed e Google Acadêmico, com aplicação dos descritores: Fisioterapia, Terapia Manual, Dor Lombar; e equivalentes em inglês. Determinou-se para inclusão, textos que relacionavam a fisioterapia com o tratamento das algias lombares; e de exclusão, artigos que não faziam a relação supracitada, não relatavam avanços na terapêutica, pesquisas com outros períodos de publicação e/ou idioma. Assim, selecionou-se nove artigos para amostragem. RESULTADOS E DISCUSSÃO: A DL crônica pode surgir por diversos motivos, incluindo: postura inadequada e esforço físico excessivo, resultando em contrações musculares exacerbadas e dor. Nesse sentido, a fisioterapia é essencial na reversão da DL, munida de recursos como: cinesioterapia, alongamentos, eletroterapia e manipulações; importantes para tratar e prevenir as algias lombares, sendo técnicas comprovadamente eficazes. Além disso, avanços tem emergido na intervenção manual de DL, através da unificação de técnicas pré-existentes e até mesmo a integração de instrumentos que antes não eram incluídos na terapêutica. Estudos apontam os ganhos da unificação entre cinesioterapia e a escola de postura no tratamento da dor na região lombar e das disfunções musculoesqueléticas. Outros estudos reforçam a eficácia de técnicas como: isostretching, estabilização segmentar, abordagem biocomportamental e as práticas integrativas e complementares, na redução da dor, aumento da flexibilidade, adaptações funcionais, força e resistência muscular. CONCLUSÃO: Verificou-se que a fisioterapia manual atua diretamente no tratamento das algias lombares crônicas inespecíficas, possuindo recursos eficazes no cuidado do paciente. Além disso, os avanços na terapêutica incluem, principalmente, a unificação de técnicas já existentes, visando melhor resultado na recuperação dos pacientes.

PALAVRAS-CHAVE: Fisioterapia; Terapia Manual; Dor Lombar. 


\section{REFERÊNCIAS}

DOMINGUES, L.; PIMENTEL, S. F. M.; CRUZ, E. B. et al. Is a combined programme of manual therapy and exercise more effective than usual care in patients with non-specific chronic neck pain? A randomized controlled trial. Clin Rehabil. v. 33, n. 12, p. 1908-1918, 2019.

GRANDE, A. M. et al. Physiotherapy Based on a Biobehavioral Approach with or Without Orthopedic Manual Physical Therapy in the Treatment of Nonspecific Chronic Low Back Pain: A Randomized Controlled Trial. Pain Med. v. 20, n. 12, p. 2571-2587, 2019.

KIM, S. K.; MIN, A.; JEON, C. et al. Clinical outcomes and cost-effectiveness of massage chair therapy versus basic physiotherapy in lower back pain patients: A randomized controlled trial. Medicine (Baltimore). v. 99, n. 12, p. 19514, 2019.

LÓPEZ, U. V. Pain management using a multimodal physiotherapy program including a biobehavioral approach for chronic nonspecific neck pain: a randomized controlled trial. Physiother Theory Pract. v. 36, n. 1, p. 45-62, 2020.

REINERT, H. B. G. et al. Manobras osteomioarticulares para o alívio da dor e restauração da mobilidade lombar. UNILUS Ensino e Pesquisa. v. 17, n. 46, p. 218-223, 2020. 


\title{
BENEFÍCIOS DA ABORDAGEM FISIOTERAPÊUTICA NA DISPAREUNIA
}

\author{
Raliane Emanuele Bonfim de Sousa'; Francieli Aparecida Feyh²; Leliane da Silva Cunha Be- \\ zerra $^{3}$; Thayná dos Santos Barbosa Feitosa ${ }^{4}$; Indiara de Alencar 5 . \\ 1,2,3,4,5 Centro Universitário da Amazônia (UNAMA). Santarém, Pará, Brasil.
}

INTRODUÇÃO: A dispareunia é uma disfunção sexual feminina definida como dor na região genital, sendo recorrente ou persistente. É classificada como superficial e profunda. A primeira, relaciona-se à dor percebida em região vulvovestibular no início da penetração, ou durante a relação sexual. $\mathrm{Na}$ segunda a dor se localiza na vagina proximal e na região hipogástrica, estando associada à dor pélvica crônica. A dispareunia pode ter causas orgânicas, comportamentais e/ou psicológicas, e está geralmente relacionada com um aumento das comorbidades e redução da qualidade de vida. OBJETIVO: Analisar informações que enfatizem os benefícios da abordagem fisioterapêutica na dispareunia. METODOLOGIA: Este estudo consiste em uma revisão bibliográfica, através de buscas nas bases de dados eletrônicas: Google acadêmico, SCIELO, PubMed. Utilizando-se os descritores em português: dispareunia, fisioterapia pélvica, disfuções sexuais feminina. Os critérios de inclusão foram artigos científicos e estudos experimentais com informações atualizadas, relacionados à atuação fisioterapêutica na dispareunia, publicados de 2011 a 2021. E como cirtérios de exclusão artigos de revisão e revisões sistemáticas. RESULTADOS E DISCUSSÃO: Dentre os 16 artigos encontrados, foram considerados 4 estudos para análise. Na abordagem fisioterapêutica, destacou-se algumas técnicas e seus benefícios. Para anagelsia, são empregues o TENS (LP:100us, F: 200Hz, T: 20 minutos) e a massagem perineal. Por meio da aplicação de dilatadores vaginais e da cinesioterapia com biofeedbeck, pode-se recuperar a flexibilidade e a propriocepção. O uso do FES (LP: 200us, F: 30Hz, T: 20 minutos) e os exercícios de Kegel fortalecem a musculatura do assoalho pélvico e proporcionam um aumento da excitação. CONCLUSÃO: Conforme os resulatos, as técnicas apresentadas neste trabalho possuem benefícios significativos quanto ao alívio da dor e melhora do desempenho sexual feminino. A fisioterapia por sua vez vem obtendo uma conduta importante para a dispareunia, pois dispõe de amplos recursos para a obtenção de resultados positivos. Faz-se necessário que haja mais estudos científicos baseados na abordagem fisioterapêutica, para que assim a prática clinica seja baseada em evidências e o tratamento seja mais eficaz.

PALAVRAS-CHAVE: Dispaurenia; Disfunção sexual; Fisioterapia. 


\section{REFERÊNCIAS}

AQUINO, Laura Helena da Costa. Intervenções Fisioterapêuticas na Dispareunia. Monografia (Graduação em Fisioterapia). Faculdade de Educação e Meio Ambiente- FAEMA. Ariquemes- Rondônia, p.55. 2019.

RODRIGUES, Cibele Nazaré Câmara et al. Influence of sexual desire the sexual function in women with dyspareunia. Brazilian Journal of Development, Curitiba, v.7, n.4, p. 34671-34682, 2021.

SILVA, Ana Paula Moreira et al. Massagem perineal melhora a dispareunia causada por tensão dos músculos do assoalho pélvico. Revista Brasileira de Ginecologia e Obstetrícia, v.39, 2017.

SILVA, Ana Paula Moreira. Abordagem fisioterapêutica da dispareunia na mulher com dor pélvica crônica: comparação entre duas técnicas. Trial clínico randomizado. Tese (Doutorado em Ciências). Universidade de São Paulo Faculdade de Medicina de Ribeirão Preto, p.68. 2018. 


\title{
BENEFÍCIOS DOS TREINOS VOLTADOS À FUNCIONALIDADE DE IDOSOS: UMA RE- VISÃO DE LITERATURA
}

\author{
Ruânderson De Albuquerque Sousa'; Paulo Henrique Ramos Pimentel². \\ ${ }^{1}$ Universidade da Amazônia (UNAMA). Santarém, Pará, Brasil; ${ }^{2}$ Universidade do Estado Pará \\ (UEPA) Santarém, Pará, Brasil.
}

INTRODUÇÃO: O processo de envelhecimento trás consigo alterações fisiológicas, que na maioria dos casos são a etiologia de alguns processos degenerativos, que pode causa a perda da funcionalidade nos idosos, fazendo com que percam sua independência para a realização de suas atividades básicas da vida diária (ABVD) e suas atividades instrumentais de vida diária (AIVD), no entanto o treino funcional (TF) vem mostrando em artigos cientifico, estudos experimentais e em relatos clínicos, eficiência para devolver ou manter a capacidade de idosos de realizar suas atividades de rotina com eficiência e segurança. OBJETIVO: Investigar na literatura existente os benefícios dos treinos voltados à funcionalidade de idosos. METODOLOGIA: Trata-se de uma revisão de literatura do tipo narrativa, utilizando as seguintes bases de dados Google Acadêmico e SciELO, foram utilizados os seguintes descritores: Fisioterapia, Treino Funcional, Idosos, Incluiu-se na pesquisa trabalhos publicados entre 2010 a 2020, na língua portuguesa. RESULTADOS E DISCUSSÃO: Foi realizada a revisão da literatura, onde foram avaliados 4 artigos, que preencheram os critérios de inclusão onde evidenciou que o Treino voltada a funcionalidade, trás mais autonomia e independência aos idosos, pois tem uma melhora notável nas áreas de equilíbrio, força muscular, coordenação motora e propriocepção. como o foco é nos padrões de movimentos e capacidades físicas que cada paciente mais necessita em sua rotina, o TF proporcionara aptidão física para a realização das ABVD e AIVD de forma especifica a cada paciente. CONCLUSÃO: Por conta do foco do treino funcional ser no preparo individualizado de cada paciente, para que o mesmo consiga realizar suas ABVD e AIVD, sua especificidade em cada paciente mostra resultados relevantes, na força muscular, mobilidade e equilíbrio, trazendo uma maior qualidade de vida em idosos, fazendo os mesmo ganhar uma maior funcionalidade e independência e preparo físico para suas rotinas.

PALAVRAS-CHAVE: Treino funcional; Idosos; Benefícios. 


\section{REFERÊNCIAS}

Da Silva-Grigoletto ME, Resende-Neto AG, La Scala Teixeira CV. Treinamento funcional: uma atualização conceitual. Rev Bras Cineantropom Desempenho Hum 2020, 22:72646.

LEAL SMO, BORGES EGS, FONSECA MA, ALVES JUNIOR ED, CADER S, DANTAS EHM. Efeitos do treinamento funcional na autonomia funcional, equilíbrio e qualidade de vida de idosas. R. bras. Ci. E Mov 2009;17(3):61-69.

PEREIRAA LM, GOMES JC, BEZERRA IL, OLIVEIRA LS, SANTOS MC. Impacto do treinamento funcional no equilíbrio e funcionalidade de idosos não institucionalizados. R. bras. Ci. e Mov 2017;25(1):79-89. 


\title{
DISTRIBUIÇÃO DE MOBILIDADE DE CRIANÇAS E JOVENS COM PARALISIA CERE- BRAL ENTRE OS NÍVEIS DO SISTEMA DE CLASSIFICAÇÃO DA FUNÇÃO MOTORA GROSSA (GMFCS)
}

\author{
Wangecy Braga Portela Júnior'; Yaritsa Gabrielly da Silva Campos²; Juciele Rodrigues de \\ Aguiar $^{3}$; Onaira Vitoria Pitombeira Santos ${ }^{4}$; Richelma de Fátima de Miranda Barbosa ${ }^{5}$. \\ 1,2,3,5 Universidade do Estado do Pará (UEPA). Santarém, Pará, Brasil; ${ }^{4}$ Universidade da Amazônia \\ (UNAMA). Santarém, Pará, Brasil.
}

INTRODUÇÃO: O Sistema de Classificação da Função Motora Grossa (GMFCS) para Paralisia Cerebral (PC) é baseado no movimento iniciado voluntariamente, com ênfase no sentar, transferências e mobilidade e classifica isto em uma escala de 5 níveis. A escala é ordinal, logo não se deve esperar que crianças e jovens com PC sejam distribuídas igualmente entre os níveis ou que as distâncias entre os níveis sejam consideradas iguais. OBJETIVO: Avaliar a distribuição de mobilidade de crianças e jovens com PC entre os níveis da GMFCS. METODOLOGIA: Trata-se de uma revisão de literatura em que foram pesquisados artigos nas plataformas digitais Scielo e PubMed, dos últimos 20 anos, usando como palavras-chave: Paralisia Cerebral; Mobilidade; GMFCS; e seus equivalentes em inglês: Cerebral Palsy; Mobility. Da seleção foram incluídas todas as pesquisas que classificassem os indivíduos pelo GMFCS e não excluísse qualquer nível, e excluídas pesquisas que não apresentassem relação com o tema e do tipo revisão de literatura. RESULTADOS E DISCUSSÃO: Foram selecionados 11 artigos que se enquadravam em todos os critérios, 45,4\% nacionais e 55,6\% internacionais (Europa e Ásia), dos 11 artigos analisados, o N amostral médio foi de 165,3, com desvio padrão de \pm 149 . A distribuição do GMFCS foi estabelecida através da média das porcentagens nos estudos: 23,43\% ( $\pm 12,3)$ classificados no GMFCS I, 19,89\% ( $\pm 9,2)$ no nível II, 14,58\% $( \pm 8,29)$ no nível III, $11,43 \%$ ( $\pm 6,54)$ no nível IV e 27,5\%( $\pm 9,6)$ no nível V. Diversos são os fatores apontados na literatura que podem influenciar na distribuição de níveis da GMFCS, deve-se destacar no entanto os fatores ambientais e extrínsecos aos indivíduos com PC, como: acessibilidade, informação, oferta de serviços, condição socioeconômica, padrões culturais e sociais. CONCLUSÃO: A GMFCS é amplamente utilizada, como prognóstico de mobilidade na PC a nível mundial e sua distribuição por ser ordinal é diversa, como observado na pesquisa. O estudo reforça a confiabilidade da escala GMFCS e incita novas pesquisas acerca do tema.

PALAVRAS-CHAVE: Paralisia Cerebral; Classificação; Mobilidade. 


\section{REFERÊNCIAS}

PALISANO, Robert et al. Sistema de classificação da função motora grossa para paralisia cerebral (GMFCS). Dev Med Child Neurol, v. 39, p. 214-223, 1997.

PODER, Rosalie et al. "O que prevê a qualidade de vida relacionada à saúde relatada por procuração de adolescentes com paralisia cerebral em Bangladesh?.” BMC saúde pública vol.20,1 18. 7 jan.2020, doi:10.1186/s12889-019-8130-1

AHMADI, Matthew N et al. "Machine Learning to Quantify Physical Activity in Children with Cerebral Palsy: Comparison of Group, Group-Personalized, and Full-Personalized Activity Classification Models." Sensores (Basileia, Suíça) vol. 20,14 3976. 17 jul. 2020, doi:10.3390/s20143976 


\title{
DOSIMETRIA DO GERADOR DE ALTA FREQUENCIA NO PROCESSO DE REPARO TECIDUAL DE FERIDAS CUTANAES: ESTUDO EXPERIMENTAL
}

\author{
Tiago Sousa da Costa ${ }^{1}$; Érica da Silva Nascimento ${ }^{2}$; Matheus Sallys Oliveira Silva ${ }^{3}$; Daliane \\ Ferreira Marinho ${ }^{4}$. \\ 1,2,3,4 Universidade do Estado do Pará (UEPA). Santarém, Pará, Brasil.
}

INTRODUÇÃO: A busca por tratamentos adequados para acelerar o processo de reparo tecidual vem ganhando destaque no meio científico, essa busca tem como objetivo minimizar os efeitos prejudiciais advindo das feridas complicadas e de difícil cicatrização. O gerador de alta frequência (AF) é um recurso promissor utilizado no tratamento de feridas e que ainda não possui na literatura atual um protocolo consolidado de aplicação, sendo utilizado empiricamente. OBJETIVO: Avaliar o processo de reparo tecidual de feridas cutâneas submetidas a diferentes parâmetros de intensidade e tempo do gerador de AF. METODOLOGIA: Estudo prospectivo, analítico, intervencional, centro único, experimental, controlado e aleatorizado. Foram utilizados 30 ratos da linhagem Wistar, divididos em seis grupos de cinco animais cada, sendo: 5 grupos experimentais, submetidos a diferentes protocolos de tratamento com AF, e 1 grupo controle. Foi realizado uma ferida padrão com um punch de 6 milímetros. O AF foi aplicado uma vez por dia durante sete dias consecutivos. Com auxílio do software Image ${ }^{\circledR}$ foi realizada a análise macroscópica, com base nos registros fotográficos da área da ferida, e posteriormente esses dados foram submetidos a estatística inferencial pelo software BioEstat ${ }^{\circledR}$ 5.0. Pesquisa devidamente aprovada pela Comissão de Ética do Uso de Animas da Universidade do Estado do Pará, protocolo n 39/2020. RESULTADOS E DISCUSSÃO: Foi constatada uma redução significativa da área da lesão entre os grupos tratados por 60 segundos com intensidade baixa (GEB1: $p=0,025)$ e média (GEM1: $p=0,014$ ) em relação ao grupo controle. O grupo GEB1 obteve redução média de $0,34 \mathrm{~cm}^{2}$, e o grupo GEM1 apresentou a maior redução da área da ferida $\left(0,35 \mathrm{~cm}^{2}\right)$. Houve diferença significativa ( $p=0.00001$ ) entre os grupos tratados por 60 segundos e os grupos tratados por 120 segundos. Os grupos de intensidade alta não obtiveram resultados significativos $(p>0,05)$, além disso, ocorreu aumento da área da lesão $\left(0,03 \mathrm{~cm}^{2}\right)$. CONCLUSÃO: Dependendo dos parâmetros utilizados o AF pode interferir de maneira benéfica ou maléfica no processo de reparo tecidual. Com a utilização adequada dos parâmetros de AF, com uma intensidade baixa ou média, por 60 segundos, ele proporcionou uma melhora significativa no processo de reparo tecidual, acelerando a cicatrização da ferida.

PALAVRAS-CHAVE: Terapia por estimulação elétrica; Cicatrização; Ozônio. 


\section{REFERÊNCIAS}

SÁ, Hoctavio Pereira et al. Estudo comparativo da ação do laser GaAlInP e do gerador de alta frequência no tratamento de feridas cutâneas em ratos: estudo experimental. ConScientiae saúde, v. 9, n. 3 , p. $360-366,2010$

SCHUH, Claudia Maria et al. Associação da alta frequência, laser de baixa potência e microcorrentes no tratamento da lesão por pressão. Cinergis, v. 18, n. 2, p. 99-103, 2017.

SOUSA, Rayssilane Cardoso de et al. Action of AlGaInP laser and high frequency generator in cutaneous wound healing. A comparative study1. Acta cirurgica brasileira, v. 30, p. 791-798, 2015. 


\title{
EFEITO DO TREINAMENTO DO ASSOALHO PÉLVICO PARA REDUÇÃO DA INCON- TINÊNCIA URINÁRIA EM PUÉRPERAS
}

\author{
Bianca Hermes de Oliveira ${ }^{1}$; Taynah Panciera D'avila²; Morgana Christmann³ \\ 123 Universidade Franciscana (UFN). Santa Maria, Rio Grande do Sul, Brasil.
}

INTRODUÇÃO: A gravidez e o parto, apesar de serem processos naturais podem causar complicações para as mulheres como incontinência urinária, problema este causado por alguma alteração no assoalho pélvico. O assoalho pélvico é um conjunto de músculos que tem como função sustentar os órgãos internos, proporcionar ação esfincteriana para a vagina, uretra e reto, além de auxiliar a passagem do feto no canal vaginal no momento do parto. Diante disso, é importante que o fisioterapeuta conheça os benefícios do treino destes músculos, para que a mulher tenha uma musculatura pélvica íntegra e forte, prevenindo possíveis alterações durante o parto e o puerpério. OBJETIVO: Analisar se o treinamento dos músculos do assoalho pélvico pode reduzir a incontinência urinária em puérperas. METODOLOGIA: Trata-se de uma revisão de literatura integrativa, onde utilizou-se a base de dados Pubmed, com uso dos seguintes descritores: "Postpartum" e "Urinary Incontinence". Foram incluídos estudos relacionados ao treino do assoalho pélvico na gravidez e no puerpério, publicados entre 2016 e 2021, apenas em inglês, disponíveis na íntegra, estudos experimentais e quase experimentais. RESULTADOS E DISCUSSÃO: De 9 artigos encontrados com os descritores, 3 foram escolhidos para análise. Um estudo avaliou que o treinamento de assoalho pélvico associado com treinamento do músculo transverso do abdome em puérperas é mais eficaz do que somente realizar exercícios para o assoalho pélvico. Associar exercícios do assoalho pélvico com fortalecimento abdominal, aeróbico e alongamentos também foi eficaz para mulheres no período pré-natal, pois demonstrou redução significativa na incontinência urinária pós parto. Entretanto, outro autor utilizou o treinamento do assoalho pélvico em puérperas que apresentavam laceração perineal grau 2, neste caso a intervenção demonstrou uma diminuição das queixas urinárias, porém não houveram diferenças significativas. CONCLUSÃO: O treinamento de assoalho pélvico se mostrou eficaz quando utilizado no pré-natal e no pós parto, porém adjunto com outros exercícios. O resultado conflitante pode ter relação com o fato de as participantes apresentarem laceração perineal e utilizarem o treinamento do assoalho pélvico isolado. Visto isso, o treinamento dessa musculatura dentro de um treino combinado é essencial para uma melhor qualidade de vida em relação à incontinência urinária em puérperas.

PALAVRAS-CHAVE: Fisioterapia; Incontinência Urinária; Pós parto. 


\section{REFERÊNCIAS}

BARACHO, E. Fisioterapia aplicada à saúde da mulher. 6. ed. Rio de Janeiro: Guanabara Koogan, 2018. $753 \mathrm{p}$.

HADIZADEH-TALASAZ, Z.; SADEGUI, R.; KHADIVZADEH, T. Effect of pelvic floor muscle training on postpartum sexual function and quality of life: A systematic review and meta-analysis of clinical trials. Taiwanese Journal of Obstetrics and Gynecology, 2019.

PTAK, M. et al. The Effect of Pelvic Floor Muscles Exercise on Quality of Life in Women with Stress Urinary Incontinence and Its Relationship with Vaginal Deliveries: A Randomized Trial. BioMed research international, 2019.

SZUMILEWICZ, A. et al. Prenatal high-low impact exercise program supported by pelvic floor muscle education and training decreases the life impact of postnatal urinary incontinence: A quasiexperimental trial. Medicine, 2020.

WU, T. et al. Early postpartum biofeedback assisted pelvic floor muscle training in primiparous women with second degree perineal laceration: Effect on sexual function and lower urinary tract symptoms. Taiwanese Journal of Obstetrics and Gynecology, 2021 


\title{
EFEITOS DA FISIOTERAPIA NAS LESÕES DE JOELHO EM ATLETAS
}

\author{
Wander Luiz da Silva Cunha ${ }^{1}$; Yana Bernarde Sá2; Antonio Jonas Rocha Silva ${ }^{3}$. \\ ${ }^{1,2}$ Universidade do Estado do Pará (UEPA). Santarém, Pará, Brasil, ${ }^{3}$ Universidade Central Paulista \\ (UNICEP), São Paulo, Brasil.
}

INTRODUÇÃO: O joelho é responsável pela maioria dos movimentos de membros inferiores e uma das articulações mais acometidas do corpo humano, pelo fato de ser utilizado como pivô, independentemente da prática de esportes. $\mathrm{O}$ aumento do interesse por atividades esportivas, bem como a vulnerabilidade e complexidade anatômica da articulação do joelho justificam um aumento crescente do número de pacientes com lesões nesse local. Dessa maneira, a fisioterapia torna-se indispensável tanto na reabilitação desses pacientes quanto na prevenção de outros agravos. OBJETIVO: Analisar a eficácia do tratamento fisioterapêutico nas lesões de joelho em atletas. METODOLOGIA: Trata-se de uma revisão de literatura, foram utilizadas as bases de dados Scielo, BVS e revistas científicas. Os descritores utilizados foram: Fisioterapia, Lesões do Joelho, Atletas e os respectivos descritores em inglês. Foram selecionados 3 artigos para este resumo e 3 excluídos. Os critérios de inclusão foram artigos que abordassem a fisioterapia nas lesões do joelho em atletas e os artigos excluídos foram os que não entrassem no critério de inclusão citado e estudos epidemiológicos. RESULTADOS E DISCUSSÃO: A primeira pesquisa abordou a eficácia de alguns métodos fisioterapêuticos para o tratamento de lesão no joelho. Foi elucidado que a eletroterapia age na regeneração de tecidos, vasodilatação e taxa metabólica; os alongamentos de MMII ajudam no ganho de ADM; a crochetagem contribui para realinhamento e restauração dos tecidos e a crioterapia reduz a inflamação e edema. $\mathrm{O}$ segundo estudo falou sobre o método pilates no tratamento de lesão patelar, utilizando 1 atleta para o experimento. Houve melhora de força, flexibilidade, capacidade respiratória e de movimento. $\mathrm{O}$ terceiro estudo, realizado com 43 pacientes, enfatizou os efeitos dos exercícios de força muscular na reabilitação do joelho, sendo realizada dinamometria isocinética e fortalecimento dos músculos extensores do joelho. $\mathrm{O}$ resultado disso foi uma diminuição significativa da dor e menor rigidez na região patelar, em todos os atletas envolvidos. CONCLUSÃO: Logo, a fisioterapia, com os métodos apresentados nesse estudo, contribui em diversos aspectos da reabilitação de joelho. Assim, a recuperação e retorno a prática esportiva de atletas é mais rápida.

PALAVRAS-CHAVE: Fisioterapia; Lesões de Joelho; Atletas. 


\section{REFERÊNCIAS}

BALDON, Rodrigo de Marche et al. Diferenças biomecânicas entre os gêneros e sua importância nas lesões do joelho. Fisioterapia em Movimento, v. 24, p. 157-166, 2011.

COHEN, Moisés et al. Patellar tendinopathy. Revista Brasileira de Ortopedia, v. 43, n. 8, p. 309$318,2008$.

FERNANDES, Rafael Ferraz; MACEDO, Christiane de Souza Guerino. Eficácia da fisioterapia na funcionalidade e dor de indivíduos com lesão no joelho submetidos a procedimento cirúrgico. Arquivos de Ciências da Saúde da UNIPAR, v. 13, n. 1, 2009.

LARA, Leisa et al. Efeito da prescrição de pilates na reabilitação da tendinite patelar: um estudo de caso. Cinergis, v. 10, n. 2, 2009.

MARN-VUKADINOVIC, Dušanka et al. Pain and outcome prediction in muscle strength rehabilitation after knee injury in recreational athletes. International Journal of Rehabilitation Research, $v$. 42, n. 2, p. 168-173, 2019. 


\title{
EFEITOS DO TRATAMENTO COM REALIDADE VIRTUAL EM PACIENTES COM DOENÇA DE PARKINSON
}

\author{
Yaritsa Gabrielly da Silva Campos ${ }^{1}$; Sara Farias Oliveira² ${ }^{2}$ José Alexandre da Silva Junior ${ }^{3}$ \\ 1,2,3Universidade do Estado do Pará (UEPA). Santarém, Pará, Brasil.
}

INTRODUÇÃO: A doença de Parkinson (DP) é uma doença neurodegenerativa diagnosticada a partir da combinação de sintomas motores que incluem bradicinesia, rigidez, tremor e instabilidade postural. A idade geralmente acometida é entre 50 e 70 anos e, especialmente nestes pacientes, existe um comprometimento da capacidade do sistema nervoso central de processar os sinais vestibulares responsáveis pelo equilíbrio. Assim, a reabilitação vestibular, através da realidade virtual (RV), permite ao usuário uma imersão em um mundo imaginário e possibilita ao terapeuta a maximização da eficácia e potencialização do efeito de intervenções existentes. OBJETIVO: Verificar os benefícios da realidade virtual aplicada em pacientes com Parkinson. METODOLOGIA: Trata-se de uma revisão da literatura, em que a coleta de dados foi realizada entre 15 e 17 de novembro de 2020 nas plataformas PubMed e Scielo, a partir dos descritores: Doença de Parkinson e Realidade Virtual e seus equivalentes em inglês. Foram encontrados 13 artigos, dos quais apenas 7 apresentaram coerência com o objetivo do trabalho, seguindo critério de inclusão: artigos em inglês e português que contemplavam os descritores, que discorriam sobre o uso da RV na reabilitação de pacientes com DP e caracterizados como estudos de intervenção; e de exclusão: artigos que utilizavam outros métodos de reabilitação e trabalhos de revisão de literatura. RESULTADOS E DISCUSSÃO: Segundo as pesquisas, o uso da RV na reabilitação de pacientes com Parkinson promove a melhora no equilíbrio e redução no risco de quedas. Estas sugerem, ainda, que a RV apresenta efeitos positivos nas variáveis velocidade e tempo de movimento, marcha, controle postural, habilidades e funcionalidade de membros superiores, além de força muscular. Outros aspectos que obtiveram melhora foram a motivação e a consequente adesão dos pacientes ao tratamento, refletindo diretamente sobre o seu bem-estar. Diante disso, a atividade lúdica oferecida pela RV e a contribuição dos feedbacks visual e auditivo oferecidos por esta intervenção terapêutica tem sido considerado como o seu grande potencial. CONCLUSÃO: A reabilitação através da RV mostrou-se eficaz na melhora da capacidade funcional e do equilíbrio corporal, reduzindo o risco de quedas, aumentando a autoconfiança e melhorando a qualidade de vida dos pacientes com DP.

PALAVRAS-CHAVE: Doença de Parkinson; Fisioterapia; Realidade Virtual. 


\section{REFERÊNCIAS}

SANTOS, Suéllen Mayara Tanaka et al. Equilíbrio em pacientes com traumatismos encefálicos que praticam natação e realidade virtual. Revista de Neurociências, v. 21, n. 1, p. 89-93, 2013.

TEIVE, Hélio A. G. et al. Sintomas e sinais motores e não motores incomuns no estágio inicial da doença de Parkinson. Arquivo Neuropsiquiatria, v. 74, n. 10, p. 781-784, outubro de 2016.

VIEIRA, Gisele de Paula et al. Realidade virtual na reabilitação física de pacientes com Doença de Parkinson. Journal of human growth and development, v. 24, n. 1, p. 31-41, 2014

ZEIGELBOIM, Bianca Simone et al. Reabilitação vestibular com realidade virtual na ataxia espinocerebelar. Audiology Communication Research, v. 18, n. 2, p. 143-147, abril-junho de 2013. 


\title{
EFEITOS DO ULTRASSOM TERAPÊUTICO APLICADO EM PACIENTES COM TENDI- NITE CALCÁRIA DO SUPRAESPINHAL
}

\author{
Danilo Reis Barbosa'; Lenise Ascenção Silva Nunes²; Juliana Nascimento da Silvaª ; Daniel \\ Garcia Paixão ${ }^{4}$; Gabriela Amorim Barreto 5 . \\ 1,2,3,5 Universidade do Estado do Pará (UEPA). Santarém, Pará, Brasil; ${ }^{4}$ Centro Universitário da \\ Amazônia - UNAMA. Santarém, Pará, Brasil.
}

INTRODUÇÃO: A tendinite calcária do supraespinhal é uma causa recorrente de algias no ombro. Os pacientes geralmente relatam piora do sintoma doloroso diante de atividades diárias, dificultando a execução tarefas simples, com consequente piora da qualidade de vida. Nesse contexto, o tratamento para tal condição inclui terapêuticas conservadoras, como a fisioterapia, com destaque para a utilização do ultrassom terapêutico (UST) no tratamento dessa patologia. OBJETIVO: Analisar os efeitos exercidos pelo UST, quando aplicado em pacientes acometidos pela tendinite calcária do supraespinhal. METODOLOGIA: Trata-se de um estudo retrospectivo baseado na literatura através de consulta na base de dados Biblioteca Virtual em Saúde (BVS). Realizou-se um recorte temporal de 2016 a 2021. As palavras-chave utilizadas foram Terapia por Ultrassom, Tendinopatia e Músculo Supra-Espinhal. Os critérios de inclusão referem-se a trabalhos que constem na plataforma escolhida, que estejam dentro do recorte temporal, que foram escritos na língua portuguesa, espanhola ou inglesa e que sejam ensaios clínicos randomizados. Como critérios de exclusão estão os trabalhos que não estejam disponíveis completos gratuitamente e que não abordem a eficácia da terapia com ultrassom no tratamento da tendinopatia do supraespinhoso. RESULTADOS E DISCUSSÃO: A tendinite calcária do músculo supraespinhoso consiste em um processo inflamatório em que há deposição de cálcio no tendão. O ultrassom é uma forma não invasiva de tratamento na reparação de lesões teciduais, sendo o método pulsátil e a baixa intensidade as modalidades mais escolhidas, o que minimiza o risco de lesões teciduais e a formação de cavitações. A terapia com emprego do ultrassom reduz a resposta inflamatória, demostrando que o ultrassom modula a inflamação, proporcionando uma maturação mais precoce das fibras de colágeno levando a um alinhamento longitudinal mais notório das fibras dos tendões tratados. Nesse contexto, a utilização do ultrassom terapêutico se apresenta como uma resposta eficaz na cicatrização e aceleração da regeneração do tecido lesado. CONCLUSÃO: Diante do exposto, o UST é de grande importância para o tratamento de pacientes com tendinite calcária do supraespinhal, garantindo a regeneração tecidual em pouco tempo e minimizando o risco de lesões teciduais futuras e na formação de pequenas cavitações locais.

PALAVRAS-CHAVE: Terapia por Ultrassom; Tendinopatia; Músculo Supra-Espinhal. 


\section{REFERÊNCIAS}

DUMOULIN, Nicolas et al. Factors Associated With Clinical Improvement and the Disappearance of Calcifications After Ultrasound-Guided Percutaneous Lavage of Rotator Cuff Calcific Tendinopathy: A Post Hoc Analysis of a Randomized Controlled Trial. The American Journal of Sports Medicine, V. 49, 2021.

LOUWERENS, Jan K.G et al. Comparing Ultrasound-Guided Needling Combined With a Subacromial Corticosteroid Injection Versus High-Energy Extracorporeal Shockwave Therapy for Calcific Tendinitis of the Rotator Cuff: A Randomized Controlled Trial. The Journal of Arthroscopy ande Related Surgery, V.36, julho 2020.

SANTAMATO, Andrea et al. Is Extracorporeal Shockwave Therapy Combined With Isokinetic Exercise More Effective Than Extracorporeal Shockwave Therapy Alone for Subacromial Impingement Syndrome? A Randomized Clinical Trial. Journal of orthopaedic \& sports physical therapy, V. 46, setembro 2016. 


\title{
EFICÁCIA DA MEDITAÇÃO PARA A REDUÇÃO DA ANSIEDADE NO CONTEXTO DE ISOLAMENTO SOCIAL DECORRENTE DA PANDEMIA POR COVID-19
}

\author{
Yana Bernarde Sá1; Daphne Teodosio de Arruda²; Lenise Ascenção Silva Nunes ${ }^{3}$; Crícia Regi- \\ na Figueira Araújo ${ }^{4}$; Renata Pessoa Portela ${ }^{5}$. \\ 1,2,3,4,5 Universidade do Estado do Pará (UEPA). Santarém, Pará, Brasil.
}

INTRODUÇÃO: A pandemia da doença Covid-19 e o isolamento social trouxeram um impacto negativo na saúde mental de muitas pessoas, sendo observado um acréscimo do sintoma de ansiedade. Logo, tornou-se de extrema importância a abordagem à saúde mental, principalmente, enfatizando práticas como a meditação. OBJETIVO: Evidenciar a eficácia da meditação na redução da ansiedade no contexto atual de isolamento social da pandemia causada pelo vírus SARS-CoV-2. METODOLOGIA: Trata-se de um estudo baseado na literatura através de consulta nas bases de dados Biblioteca Virtual em Saúde (BVS). Realizou-se um recorte temporal de 2020 a 2021. As palavras-chave utilizadas foram Meditação, Ansiedade e Pandemias. Os critérios de inclusão referem-se a trabalhos que constem nas plataformas escolhidas, que estejam dentro do recorte temporal e que foram escritos na língua portuguesa ou inglesa. Como critérios de exclusão estão os trabalhos que não abordam a eficácia da meditação na redução da ansiedade durante a pandemia por Covid-19. RESULTADOS E DISCUSSÃO: O primeiro estudo abordou o impacto psicológico do confinamento devido à pandemia COVID-19 e a prática da meditação. Participaram 412 pessoas na pesquisa e durante este primeiro estágio de confinamento, os participantes relataram sintomas de ansiedade, depressão e estresse pós-traumático. Foi enfatizado que em indivíduos com a idade mais avançada foi encontrada uma maior frequência na prática da meditação, o que gerou menos estresse e ansiedade. Dessa maneira, a meditação foi revelada como uma ajuda contra a ansiedade durante o período de isolamento social na pandemia de COVID-19. Já o segundo estudo abordou o impacto positivo da meditação na saúde mental de professores durante o surto de Covid-19. Foram avaliados 66 professores, de forma híbrida, e divididos em 2 grupos, LR (baixa resiliência), e HR (alta resiliência), já que a habilidade de resiliência foi considerada o fator mais importante antes da pesquisa começar. Os dois grupos receberam um curso de meditação de 8 semanas. Avanços positivos após essas semanas foram observadas em ambos os grupos nos níveis de ansiedade e bem-estar psicológico, sendo maiores no grupo HR. CONCLUSÃO: Logo, a meditação mostrou eficácia na redução da ansiedade durante a pandemia ocasionada pelo vírus SARS-CoV-2.

PALAVRAS-CHAVE: Ansiedade; Meditação; Pandemias. 


\section{REFERÊNCIAS}

JIMÉNEZ, Óliver; SÁNCHEZ-SÁNCHEZ, Laura C.; GARCÍA-MONTES, José M. Psychological impact of COVID-19 confinement and its relationship with meditation. International Journal of Environmental Research and Public Health, v. 17, n. 18, p. 6642, 2020.

MATIZ, A ; FABBRO, F .; PASCHETTO, A .; CANTONE, D .; PAOLONE, AR; CRESCENTINI, C. Positive Impact of Mindfulness Meditation on Mental Health of Female Teachers during the COVID-19 Outbreak in Italy. International Journal of Environmental Research and Public Health. V. 17, n. 18, 2020.

SILVA, Hengrid Graciely Nascimento; DOS SANTOS, Luís Eduardo Soares; DE OLIVEIRA, Ana Karla Sousa. Efeitos da pandemia do novo Coronavírus na saúde mental de indivíduos e coletividades/Effects of the new Coronavirus pandemic on the mental health of individuals and communities. Journal of Nursing and Health, v. 10, n. 4, 2020. 


\title{
EQUOTERAPIA COMO FERRAMENTA DE REABILITAÇÃO NA PARALISIA CEREBRAL
}

\author{
Maria Beatriz Cardoso Magalhães Damasceno ${ }^{1}$; Byanca Soares da Silva²; Rafaela Pereira \\ Cunha $^{3}$; Jennifer Maia Pessoa ${ }^{4}$; Mariana dos Anjos Furtado de Sá ${ }^{5}$ \\ 1,2,3,4,5 Universidade do Estado do Pará (UEPA). Santarém, Pará, Brasil.
}

INTRODUÇÃO: A paralisia cerebral (PC) é uma das principais disfunções motoras não progressivas da infância, sendo caracterizada por comprometimentos neuropsicomotores observados nos movimentos, postura, tônus e cognição. Nesse sentido, a equoterapia vem se mostrando como uma técnica positiva para portadores de PC, pois ao utilizar o cavalo como recurso terapêutico, consegue estimular tanto a função motora quanto a sensorial e cognitiva, atuando de forma global no corpo. OBJETIVO: Analisar as repercussões da prática de equoterapia em indivíduos com paralisia cerebral. METODOLOGIA: Trata-se de um estudo retrospectivo baseado na literatura através de consulta na base de dados Biblioteca Virtual em Saúde (BVS) e PUBMED, mediante uso dos seguintes descritores em saúde: Terapia Assistida por Cavalos e Paralisia Cerebral e seus correlatos em inglês. Foram incluídos estudos publicados no período de 2016 a 2021, nos idiomas português e inglês e que sejam ensaios clínicos randomizados. Foram excluídos estão os artigos que não estejam disponíveis completos gratuitamente e que não abordem a temática proposta. RESULTADOS E DISCUSSÃO: Inicialmente foram encontrados 63 estudos na plataforma BVS e 9 na PUBMED, após aplicação dos critérios de elegibilidade, 4 artigos foram selecionados para análise. No geral, os estudos basearam-se em analisar principalmente a mobilidade funcional, força muscular, postura, espasticidade, interação social e qualidade de vida no grupo de crianças, sendo que todos os trabalhos demonstraram resultados significativamente positivos em seus parâmetros de análise. A amostra dos estudos foi consideravelmente ampla, sendo superior à 40 participantes em 3 deles. Quanto ao período das intervenções foi possível observar que todas apresentaram um período igual ou superior à dez sessões. CONCLUSÃO: Portanto, de acordo com os estudos encontrados é possível observar que, a equoterapia é um instrumento terapêutico que proporciona resultados positivos em indivíduos com paralisia cerebral. Sendo possível observar melhora em aspectos biomecânicos e na funcionalidade, refletindo em uma melhor qualidade de vida. Diante disso, salienta-se também a necessidade de mais estudo voltados para esta temática, tendo em vista o número reduzido de artigos selecionados.

PALAVRAS-CHAVE: Equoterapia; Paralisia Cerebral; Reabilitação. 


\section{REFERÊNCIAS}

ALIENE, Laura et al. Short-term and long-term effects of riding for children with cerebral palsy gross motor functions. BioMed research international, v. 2018.

LUCENA-ANTÓN, David; ROSETY-RODRÍGUEZ, Ignacio; MORAL-MUNOZ, Jose A. Effects of a hippotherapy intervention on muscle spasticity in children with cerebral palsy: A randomized controlled trial. Complementary therapies in clinical practice, v. 31, p. 188-192, 2018.

MELLO, Enilda Marta Carneiro de Lima et al. A influência da equoterapia no desenvolvimento global na paralisia cerebral: revisão da literatura. Cadernos de Pós-Graduação em Distúrbios do Desenvolvimento, v. 18, n. 2, p. 12-27, 2018.

PRIETO, Alessandra Vidal. Efeitos da frequência semanal de um programa de equoterapia na função motora grossa e no desempenho funcional em crianças com paralisia cerebral. 2017.

TSIFTZOGLOU, Karina et al. Evidências em equoterapia na paralisia cerebral: uma revisão de literatura a partir da base PEDro. Cadernos de Pós-Graduação em Distúrbios do Desenvolvimento, v. 19, n. 1, p. 36-50, 2019. 


\title{
FISIOTERAPIA NA REABILITAÇÃO DE DOENÇAS OSTEOMIOARTICULARES RELA- CIONADO AO TRABALHO (DORT): REVISÃO INTEGRATIVA
}

\author{
Juliana Nascimento da Silva'; José Alexandre da Silva Júnior². \\ 1,2Universidade do Estado do Pará (UEPA). Santarém, Pará, Brasil.
}

INTRODUÇÃO: As doenças osteomioarticulares relacionadas ao trabalho (DORT), constituem causa importante de absenteísmo no trabalho, gerando perdas produtivas e econômicas, além de limitações e sofrimento aos acometidos. Diante disso, evidencia-se a necessidade de assistência específica e qualificada para esses distúrbios, destacando-se a conduta fisioterapêutica, que oferta prevenção e reabilitação aos pacientes. OBJETIVO: Analisar a atuação da fisioterapia na reabilitação de pacientes portadores de disfunções osteomioarticulares relacionadas ao trabalho. METODOLOGIA: A coleta de dados, para a presente revisão, foi realizada em artigos dos anos 2020-2021, na base de dados Google Acadêmico, com aplicação dos descritores: Fisioterapia, Reabilitação, Transtornos Traumáticos Cumulativos; e equivalentes em inglês. Selecionou-se, a partir da busca, um total de oito artigos, que respeitaram os critérios estabelecidos. Como critérios de inclusão, considerou-se textos que relacionavam a fisioterapia com o tratamento de distúrbios osteomioarticulares associados ao trabalho; e de exclusão, artigos que não faziam a correlação supracitada, trabalhos com outros períodos de publicação e/ou idioma. RESULTADOS E DISCUSSÃO: Os trabalhadores acometidos por DORT possuem um quadro clínico complexo, incluindo: dor, parestesia, fadiga, diminuição de força e amplitude de movimento, podendo causar incapacidade laboral temporária ou permanente. Diante disso, a fisioterapia exerce essencial papel na avaliação e reabilitação dos trabalhadores acometidos por tais distúrbios, possuindo competência em considerar o quadro clínico, evolução, etiologia, fatores ocupacionais e delimitar a terapêutica. Um estudo de Sousa et al. (2020), indicou bons resultados com aplicação de cinesioterapia em pacientes com DORT, através da diminuição da dor, melhora da funcionalidade e flexibilidade, e ganho de força muscular. Para além, outro estudo feito pelo Departamento de Saúde do Reino Unido, afirma que a fisioterapia é eficaz no gerenciamento e tratamento de pacientes com doenças musculoesqueléticas, apontamento confirmado por outras pesquisas que concluíram que a prática fisioterapêutica promove a restauração do movimento e função, e alívio/ resolução da dor, utilizando-se para isso, de alongamentos, exercícios de fortalecimento, estimulação elétrica, cinesioterapia, hidroterapia e acupuntura. CONCLUSÃO: Nota-se que a fisioterapia é eficaz na reabilitação de pacientes com DORT, possuindo vários recursos para esse fim. Ademais, exerce papel na prevenção, atenuação/resolução de sintomas da doença e possui capacidade de promover completa reabilitação.

PALAVRAS-CHAVE: Fisioterapia; Reabilitação; Transtornos Traumáticos Cumulativos. 


\section{REFERÊNCIAS}

LIMA, J. C. et al. Perfil, sinais e sintomas de trabalhadores com LER/DORT de Minas Gerais Notificações de LER/DORT no estado de Minas Gerais/Profile, signs and symptoms of work-related musculoskeletal disorders in the State of Minas

Gerais. Brazilian Journal of Development, v. 6, n. 7, p. 46042-46061, 2020.

DUARTE, T. V.; LIMA, M. F. Aplicação da ginástica laboral na prevenção de ler/dort no setor administrativo da prefeitura municipal de paracatu-mg. Humanidades e tecnologia (FINOM), v. 23, n. 1, p. 383-404, 2020.

NASCIMENTO, J. L. S. Lesões musculoesqueléticas em trabalhadores da indústria: análise dos fatores relacionados à concessão de auxílio-doença e efetividade de intervenções ergonômicas para controle da dor. 2021.

BORGES, Y. S.; BAGATINI, M. A.; GALVAN, T. C. Perfil epidemiológico de pacientes atendidos na clínica de fisioterapia de um frigorífico: um estudo retrospectivo. Revista Contexto \& Saúde, v. 20, n. 40, p. 43-50, 2020.

SOARES, C. et al. Lesões por esforços repetitivos e distúrbios osteomusculares relacionados ao trabalho (ler/dort): papel dos profissionais da saúde. CADERNOS DE EDUCAÇÃO, SAÚDE E FISIOTERAPIA, v. 7, n. 14, 2020. 


\section{HIDROTERAPIA NO TRATAMENTO DE FIBROMIALGIA: RELATO DE EXPERIÊNCIA}

\section{Mayara Renata Lima Mota ${ }^{1}$; Thiago da Costa Alexandrino²; John Henry de Oliveira Vale ${ }^{3}$.}

${ }^{1}$ Universidade do Estado do Pará (UEPA). Santarém, Pará, Brasil; ${ }^{2}$ Universidade do Estado do Pará (UEPA). Santarém, Pará, Brasil; ${ }^{3}$ Universidade do Estado do Pará (UEPA). Santarém, Pará, Brasil

INTRODUÇÃO: A fibromialgia é uma doença crônica, caracterizada por uma dor musculoesquelética difusa associada a fadiga. A hidroterapia é um dos recursos fisioterapêuticos utilizados para tratamento de pacientes com diagnóstico de fibromialgia. OBJETIVO: Relatar quais são os benefícios da hidroterapia em pacientes com diagnóstico de fibromialgia. METODOLOGIA: O seguinte trabalho foi elaborado a partir de vivência de residentes do programa de residência multiprofissional em Ortopedia e Traumatologia da Universidade do Estado do Pará, no qual realizam atendimentos no setor de hidroterapia durante os meses de junho a setembro de 2021. Os atendimentos eram realizados de duas a três vezes por semana, com duração de 45 minutos. RESULTADOS E DISCUSSÃO: Dentre os pacientes identificou-se a prevalência do sexo feminino, com a média de idade de 45 anos. Os pacientes atendidos tinham relatos de dores globais que limitavam algumas atividades de vida diária e consequentemente geravam diminuição da amplitude de movimento. Cada sessão era composta de aquecimentos, alongamentos e exercícios ativos para membro superiores, inferiores e coluna vertebral, todos os exercícios eram realizados dentro da amplitude de movimento do paciente. Após estes pacientes iniciarem o tratamento na hidroterapia percebe-se que os mesmo apresentavam melhora do quadro álgico, fadiga e melhora da funcionalidade. Tais resultados se dão pelos princípios terapêuticos da hidroterapia, que promove o relaxamento muscular, aumento da circulação sanguínea, assim como, possibilita a realização de movimentos em quaisquer amplitude de movimento de modo indolor e prazeroso. Tal prática tem impacto positivo no tratamento da fibromialgia, bem como na promoção do bem-estar, regulação do sono e minimização dos sintomas e síndromes manifestadas em decorrência da patologia. CONCLUSÃO: Diante disso percebe-se que o tratamento de fibromialgia através da hidroterapia oportuniza ao paciente mais qualidade de vida, tanto funcional, quanto social e profissional.

PALAVRAS-CHAVE: Fibromialgia; Hidroterapia; Fisioterapia. 


\section{REFERÊNCIAS}

DA SILVA, Claudia Kenia Fernandes et al. Análise de diferentes protocolos dos exercícios aeróbicos na dor em mulheres com fibromialgia: uma revisão sistemática. Research, Society and Development, v. 10, n. 3, p. e13710313115-e13710313115, 2021.

GOMES, Artur Bruno Silva et al. A IMPORTÂNCIA DO EXERCÍCIO NA TERAPÊUTICA DA FIBROMIALGIA. Revista Multidisciplinar em Saúde, v. 2, n. 3, p. 109-109, 2021.

SORIANI, Giovana Gomez; FRITZEN, Leonardo Dos Santos; YONAMINE, Cristhiane Ayumi. Comparação da Terapia Aquática com a Terapia Solo na Sintamomatologia de Indíviduos com Fibromialgia. Publicação Eventos Científicos, 2021. 


\section{O DESEMPENHO DOS OMBROS DOS PRATICANTES DE ESPORTES OVERHEAD}

\section{Thayane Nataly Maia de Albuquerque'; Marcos Fábio Ribeiro de Abreu²}

${ }^{1}$ Instituto Esperança de Ensino Superior (IESPES). Santarém, Pará, Brasil; ${ }^{2}$ Universidade Paulista (UNIP). Santarém, Pará, Brasil.

INTRODUÇÃO: Os desportos overhead são caracterizados pela elevação dos membros superiores acima da cabeça, como por exemplo voleibol, basquete, tênis, natação, entre outros. Nesses esportes os ombros são submetidos a movimentos bruscos, com grandes velocidades e amplitudes de movimento. O ombro é a articulação com maior mobilidade, e isto ocorre porque o úmero tem sua extremidade convexa, ligado na glenóide, e côncava, em uma espécie de bola e soquete, possibilitando movimentos de rotação em sua amplitude. OBJETIVO: Avaliar a força e amplitude de movimento articular nos ombros durante os movimentos de rotação interna e rotação externa comparando a mesma, entre os ombros dominantes e não dominantes. METODOLOGIA: Utiliza-se a revisão de literatura, com base em autores que discorrem sobre a função do membro superior dominante nos esportes overhead, além de trabalhos publicados entre 2017 a 2021, no idioma português, disponíveis nos bancos de dados científicos disponíveis. Os autores utilizados, usaram instrumentos para medir a amplitude de rotação interna e externa do ombro, o Baseline Bubble Inclinometer, através do inclinômetro, que permite a medição em graus. Assim, para avaliação da força muscular, foi utilizado o instrumento, o Lafayette Manual Muscle Testing System, trata-se de um dispositivo ergonômico que quantifica objetivamente a força muscular, capaz de registar a força máxima fornecendo precisão na leitura e o tempo que foi necessário para atingir a mesma. RESULTADOS E DISCUSSÃO: Os resultados, com base na metodologia utilizada, apontam a existência de diferenças consideráveis, de articulação entre os ombros dominantes e não dominantes, assim como uma amplitude superior entre a rotação externa para com a rotação interna. CONCLUSÃO: Medidas de prevenção devem ser adotadas, como evitar quedas condicionadas, fazer uso de equipamentos de proteção na prática individual de cada esporte, avaliação fisioterapêutica periódica. De todo modo, os esportistas de overhead, apresentados neste estudo, por meio dos autores estudados, apresentam força muscular superior, bem como sua rotação externa é superior a rotação interna quando relacionada ao membro não dominante.

PALAVRAS-CHAVE: Overhead; Ombro; Rotação. 


\section{REFERÊNCIAS}

Campos, C. E., Medeiros, P. E. S., Couto, C. R., Cardoso, C. L. M. e Andrade, A. G. P. (2016). Avaliação da força máxima isométrica de rotadores internos e externos do ombro de tenistas juvenis. Conexão Ciência (Online), 10(2), 01-09.

Ferreira AAF. Síndrome do impacto e lesão do manguito rotador. In: Pardini AG. Clínica ortopédica: atualização em cirurgia do ombro. Rio de Janeiro: Medsi; 1999. p. 117-26.

Jesus, L. A. e Medrado, A. R. A. P. (2015). Análise de capacidade funcional e métodos de avaliação de membros superiores em mulheres submetidas ao tratamento de câncer da mama: uma revisão sistemática. Revista Pesquisa em Fisioterapia, 5(3), 286-299. 


\section{O DIÁLOGO ENTRE IDOSOS E ESTUDANTES DE FISIOTERAPIA EM UMA UNIDADE MUNICIPAL DE SAÚDE EM BELÉM/PA}

\section{Jennyfer Karolaine dos Santos Lima'; Ana Lúcia Farias Vidal'; Fábia Alves Ramôa ${ }^{3}$; Thayna- ra Rodrigues Gomes ${ }^{4}$; Tainá Alves Teixeira ${ }^{5}$}

1,2,3,4 Universidade do Estado do Pará (UEPA). Belém, Pará, Brasil. ${ }^{5}$ Universidade do Estado do Pará (UEPA). Belém, Pará, Brasil.

INTRODUÇÃO: A abordagem biopsicossocial é essencial para apurar não somente o aspecto biológico, mas, também, os sentimentos, crenças, valores e estilos de vida do paciente. Olhar para o indivíduo em sua integralidade permite ao profissional de saúde entender o paciente em sua multidimensionalidade, além de possibilitar a humanização e uma investigação das queixas a partir de aspectos diversos. OBJETIVO: Analisar o diálogo entre idosos e estudantes de fisioterapia em uma UMS em Belém/PA. METODOLOGIA: Realizaram-se entrevistas de caráter qualitativo com idosos em uma Unidade Municipal de Saúde em Belém do Pará, nas perguntas feitas, destacaram-se os temas acerca de hábitos saudáveis, se sentiam dor em regiões do corpo e se utilizavam medicações, entretanto, valeu-se a experiência da escuta durante a entrevista. Para a busca de artigos, utilizou-se a base de dados Scientific Electronic Library Online (Scielo) com as palavras-chave: "Modelos Biopsicossociais"; "Idoso" e "Comunicação", de tal forma, foram encontrados 4.276 artigos com a palavra-chave "Idoso", 5.592 artigos com a palavra-chave "Comunicação", 1 artigo com a palavra-chave "Modelos Biopsicossociais" publicados no Brasil, destes, utilizaram-se 5, que agregaram diante da temática do estudo. RESULTADOS E DISCUSSÃO: Registraram-se 19 idosos que buscavam atendimento na UMS para uma única queixa biológica, caracterizando o modelo biomédico. É válido ressaltar que tal modelo não abrange todos os prismas do ser humano e possui baixa resolutividade, assim, pontua-se o modelo biopsicossocial, que corrobora a importância da escuta qualificada e do acolhimento dos pacientes, a fim de promover um atendimento integralizado. No modelo biopsicossocial, o profissional de saúde possui discernimento acerca de como problemas psicológicos e/ou sociais afetam a saúde, pois dificultam o enfrentamento das doenças. Assim, a interação terapeuta-paciente promove a humanização do atendimento e maior resolutividade do tratamento, considerando as circunstâncias sociais, éticas, educacionais e psíquicas dos sujeitos envolvidos, tendo em vista que os fatores psicossociais podem operar para facilitar, manter ou modificar o curso da doença. CONCLUSÃO: A escuta ativa demonstra a humanização no que tange à prevenção, promoção, diagnóstico e reabilitação dos pacientes, além de entender os aspectos multietiológicos das suas queixas. Ressalta-se que a experiência também foi enriquecedora para os estudantes.

PALAVRAS-CHAVE: Modelos Biopsicossociais; Idoso; Comunicação. 


\section{REFERÊNCIAS}

ANDERSON, Maria Inez P.; RODRIGUES, Ricardo Donato. O paradigma da complexidade e os conceitos da Medicina Integral: saúde, adoecimento e integralidade. Revista Hospital Universitário Pedro Ernesto (TÍTULO NÃO-CORRENTE), v. 15, n. 3, p. 242-252, 2016.

CASTANEDA, Luciana. O Cuidado em Saúde e o Modelo Biopsicossocial: apreender para agir. In: CoDAS. Sociedade Brasileira de Fonoaudiologia, 2019.

OLIVEIRA, Maria José Santos et al. A escuta ativa como estratégia de humanização da assistência em saúde. Saúde e Desenvolvimento Humano, v. 6, n. 2, p. 33-38, 2018.

PINHEIRO, Simone Bruschi. Atenção em saúde: Modelo biomédico e biopsicossocial, uma breve trajetória. Revista Longeviver, 2021

SANTOS, A. B. Escuta qualificada como ferramenta de humanização do cuidado em saúde mental na Atenção Básica. APS EM REVISTA, [S. l.], v. 1, n. 2, p. 170-179, 2019. 


\title{
O TRABALHO DOCENTE E AS REPERCUSSÕES NA QUALIDADE DE VIDA DO PRO- FISSIONAL: RELATO DE CASO
}

\author{
Monize de Melo e Sousa'; Iranete Corpes de Oliveira França² \\ 1,2 Universidade Superior da Amazônia (UNAMA). Belém, PA, Brasil.
}

INTRODUÇÃO: O mundo tem enfrentado, desde o final de 2019, uma grande crise sanitária em decorrência do surgimento do novo corona-vírus, que impôs à população o período de quarentena, ocasionando, assim, o desdobramento de atividades em home office. Consequentemente, os profissionais da educação, a fim de dar continuidade às aulas, foram expostos de forma significativa a jornadas excessivas de trabalho e à fadiga mental, que contribuem para uma desfavorável qualidade do sono e de vida, e favorecem a manifestação da síndrome de Burnout. OBJETIVO: Analisar a qualidade do sono de uma professora em home office, observando, dentro desse novo cenário de trabalho, como esse fator interfere na qualidade de vida e na manifestação da síndrome de Burnout. METODOLOGIA: O trabalho foi aprovado pelo Comitê de Ética do ICES-UNAMA, com número de parecer 3.841.641. Trata-se de um relato de caso realizado na residência de uma professora de educação física e baseou-se em artigos científicos e em respostas obtidas através da aplicação da Escala de Pittsburhg, para avaliação da qualidade do sono, do TQWL-42-Questionário de Avaliação da Qualidade de Vida no Trabalho e do Questionário JBEILI, para identificação preliminar de Burnout. RESULTADOS E DISCUSSÃO: Professora J.T.A.C, 41 anos, trabalha atualmente em home office durante o período da manhã, e é responsável por todas as turmas do Ensino Infantil e Fundamental. Conforme o questionário TQWL-42, apresentou uma qualidade de vida satisfatória. Entretanto, com frequência, sente-se cansada durante o trabalho, julgando-o exaustivo, além de raramente poder expressar suas opiniões devido a julgamentos. Ademais, sente-se insatisfeita consigo mesma e com o tempo para atividades de lazer. Com relação ao questionário JBEILI, apresentou um score de 46 pontos, indicando fase inicial de Burnout e, na escala de Pittsburhg, constou má qualidade do sono. CONCLUSÃO: Conforme as informações coletadas, conclui-se que a qualidade de vida da professora J.T.A.C é satisfatória. Porém, é importante atentar para fatores que se afastaram da média, como a exaustão no trabalho e a insatisfação consigo mesma, além de indicativos da fase inicial de Burnout e má qualidade do sono, que podem contribuir para o desenvolvimento de uma desfavorável qualidade de vida.

PALAVRAS-CHAVE: Docente; Qualidade de vida; Sono. 


\section{REFERÊNCIAS}

CREPALDI, T. O. M.; CARVALHAIS, J. D. de J. A contribuição da má qualidade do sono na qualidade de vida no trabalho de professores: uma revisão. Brazilian Journal of Development, Curitiba v. 6, n. 10 , p. $75044-75057$, out. 2020 .

MOREIRA, H. de R.; FARIAS, G. O.; BOTH, J.; NASCIMENTO, J. V. Qualidade de vida no trabalho e síndrome de burnout em professores de educação física do estado do Rio Grande do Sul, Brasil. Revista Brasileira de Atividade Física \& Saúde, Florianópolis, v. 14, n. 2, p. 115-122, 2012.

ROCHA, Guilherme Nobre. Qualidade de vida no trabalho e risco da Síndrome de Burnout em professores da educação de jovens e adultos. Trabalho de Conclusão de Curso (Graduação em Enfermagem) - Universidade Federal de Mato Grosso, Instituto de Ciências da Saúde, Sinop, 2015. 


\title{
OS BENEFÍCIOS DO USO DO LED NO TRATAMENTO DA ACNE VULGAR
}

\author{
Crícia Regina Figueira Araújo'; Gabriel Matheus Batista Brito²; Tafne Moraes Pereira ${ }^{3}$; \\ Thiago Pereira Lemos ${ }^{4}$; Marina Silva Nicolau Taketomi ${ }^{5}$. \\ 1,2,3,4,5 Universidade do Estado do Pará (UEPA). Santarém, Pará, Brasil.
}

INTRODUÇÃO: A acne é uma doença inflamatória crônica da pele, caracteriza-se pela formação de lesões cutâneas como, comedões abertos e fechados que são lesões não inflamatórias, pápulas, pústulas ou nódulos/quistos que são lesões inflamatórias e cicatrizes que são resultado da acne inflamatória e estão associadas a um aumento ou a perda de colágeno. O LED (do inglês Light Emitting Diode), é um dispositivo de luz com diferentes comprimentos de ondas, absorvida pelas células e transformada em energia vital, estimulando e aumentando as funções celulares, como a síntese de colágeno. A luz azul é comumente indicada para o tratamento da acne e é a mais utilizada pelos profissionais pelo conhecimento de sua ação bactericida, a luz âmbar é comumente indicada por sua ação anti-inflamatória. OBJETIVO: Evidenciar por meio de revisão de literatura os benefícios do uso do LED no tratamento da acne vulgar. METODOLOGIA: Foram coletados dados de plataformas digitais, nos idiomas português e inglês, através das palavras-chave: acne vulgar, benefícios e LED, no período de 2017 a 2021. Incluídos 3 artigos que evidenciaram os benefícios do LED no tratamento da acne vulgar, excluídos 34 artigos que não tiveram relação como a temática. RESULTADOS E DISCUSSÃO: Um estudo realizado com 31 pacientes o qual foi obtido resultado satisfatório na acne grau II em $52 \%$ desses pacientes. Foi utilizada a luz azul em um lado da face e o outro lado foi usado como controle. Outro estudo, foram analisados 30 casos de acne inflamatória em ambos os gêneros, através da fotoexposição ao LED azul (415nm) em 16 sessões de 15 minutos por aplicação. As análises dos resultados foram feitas a partir de fotos tiradas no pré e pós-procedimento e por elas foram constatadas melhoras significativas na redução da oleosidade cutânea e no quadro de pústulas promovendo a satisfação pessoal, assim, aumentando a autoestima dos participantes. CONCLUSÃO: Portanto, o uso do LED demostrou muitos benefícios no tratamento da acne vulgar, por exemplo: na resolução do processo inflamatório, redução da oleosidade da pele, clareamento das manchas ocasionadas pela acne, efetividade na cicatrização tecidual e diminuição no surgimento de novas lesões.

PALAVRAS-CHAVE: Acne vulgar; Benefícios; LED. 


\section{REFERÊNCIAS}

HENTGES, Raíssa Camargo et al. USO DO LASER E DO LED NO TRATAMENTO DA ACNE VULGAR: UMA REVISÃO DA LITERATURA. In: Congresso Internacional em Saúde. 2021. MOREIRA, Cátia Joceline Silva. Acne: relação hospedeiro-patogeno. 2019. Tese de Doutorado. YAMADA, Felipe Ryuichi; DA SILVA, Mônica Maciel; SCASNI, Katiuscia Rosette. O uso do LED para o tratamento da acne. Surgical \& Cosmetic Dermatology, v. 9, n. 4, pág. 316-323, 2017. 


\title{
OS EFEITOS DA LASERTERAPIA DE BAIXA POTÊNCIA NA CICATRIZ DE ACNE
}

\author{
Gabriel Matheus Batista Brito" Crícia Regina Figueira Araújo²; Tafne Moraes Pereira³ Ma- \\ rina Silva Nicolau Taketomi ${ }^{4}$ \\ 1,2,3,4 Universidade do Estado do Pará (UEPA). Santarém. Pará. Brasil.
}

INTRODUÇÃO: A acne é uma enfermidade crônica de etiologia multifatorial que causa obstrução e inflamação do folículo pilossebáceo. A partir do estímulo das glândulas sebáceas, por fatores ambientais ou endógenos, há um aumento da secreção de sebo levando a hiperqueratinização com obstrução do canal folicular. Este processo causa uma reação inflamatória local, induzindo o aparecimento das lesões acneicas. A presença de cicatrizes de acne tem impacto negativo na qualidade de vida de um indivíduo, pois induzem a perda de confiança em sua aparência, reduzindo sua autoestima, e levando a sentimentos de exclusão e depressão, o que afeta tanto a sua vida profissional, quanto a vida pessoal. Vários tipos de lasers são utilizados para o tratamento de acne vulgar. Embora sejam eficazes, em geral, diferem em termos de efeitos colaterais e resultados clínicos, dependendo do fototipo de pele e do tipo de cicatriz da acne do paciente. OBJETIVO: Conhecer os efeitos da laserterapia de baixa potência na cicatriz de acne. METODOLOGIA: Trata-se de uma revisão de literatura através de consulta na base de dados PUBMED e Google Acadêmico. Foram definidos como critérios de inclusão: artigos publicados entre 2010 e 2021, nos idiomas português e inglês. Foram excluídos artigos duplicados ou que abordassem a utilização da laserterapia em outras disfunções. RESULTADOS E DISCUSSÃO: Foram encontrados 306 artigos nas plataformas utilizadas, após aplicação dos critérios estabelecidos, foram selecionados 3 para análise. Através da revisão dos artigos, observou-se que o laser é um dispositivo que produz radiação eletromagnética e possui algumas características: ela é monocromática, coerente e colimada. Por essas propriedades especiais, o laser é utilizado em diversas aplicações: médicas, anti-inflamatório, regenerador e analgésico. Os lasers utilizados no tratamento de cicatrizes de acne agem promovendo destruição das camadas superficiais da pele, atuando no processo de remodelação e melhorando a textura e o relevo da pele. CONCLUSÃO: Conclui-se que a terapia a laser traz resultados bastante satisfatórios. A característica fotobiomoduladora do laser estimula a formação de colágeno e elastina, melhorando o aspecto das cicatrizes dos pacientes. Observou-se também que os efeitos da terapia são potencializados com o uso associado de produtos cosméticos na região afetada.

PALAVRAS-CHAVE: Acne Vulgar; Cicatriz; Terapia com Luz de Baixa Intensidade. 


\section{REFERÊNCIAS}

PASCHOAL, F. M.; ISMAEL, B.; PALU, A. P. The effect of light in the treatment of acne vulgaris. Surgical \& Cosmetic Dermatology, v. 2, n. 2, p. 117-123. 2010.

SADICK, N. S.; CARDONA, A. Laser treatment for facial acne scars: A review, Journal of Cosmetic and Laser Therapy, v. 20, n. 7-8, p. 424-435. 2018. DOI: 10.1080/14764172.2018.1461230

SARAIVA, T. A. et al. Laser terapy in the treatment of vulgar acne. Revista Brasileira Militar de Ciências, v. 6, n. 15. 2020. 


\title{
PANORAMA EPIDEMIOLOGICO DAS MALFORMAÇÕES CONGÊNITAS DO APARELHO OSTEOMUSCULAR NO ESTADO DO PARÁ, BRASIL
}

\author{
Tiago Sousa da Costa ${ }^{1}$; Matheus Sallys Oliveira Silva ${ }^{2}$; Debora Carolina Santos do Nascimen- \\ to ${ }^{3}$. \\ ${ }^{1,2,3}$ Universidade do Estado do Pará (UEPA). Santarém, Pará, Brasil.
}

INTRODUÇÃO: As malformações congênitas são definidas como alterações funcionais ou estruturais, que se manifestam antes do nascimento, logo ao nascimento ou tardiamente em etapas mais avançada da vida. Resultando em incapacidade física ou mental. As malformações do aparelho osteomuscular são as de maior prevalência, essas podem atingir apenas um segmento corporal ou apresentar-se de forma generalizada. Sua etiologia não é bem definida, sendo associada a fatores originados antes do nascimento, seja genético, ambiental ou desconhecido. OBJETIVO: Descrever as características epidemiológicas das malformações congênitas do aparelho osteomuscular no estado do Pará, Brasil, no período de 2016 a 2019. METODOLOGIA: Trata-se de um estudo descritivo com abordagem quantitativa. Realizado através de dados secundários do Sistema de Informação sobre Nascidos Vivo, referente ao período de 2016 a 2019. A coleta de dados foi realizada utilizando as variáveis: Peso ao nascer, sexo, consultas no pré-natal, tipo de parto e idade da mãe. Posteriormente, esses dados foram submetidos à estatística descritiva pelo software BioEstat ${ }^{\circledR}$ 5.0. RESULTADOS E DISCUSSÃO: De 556.525 nascimentos notificados no estado do Pará no período de 2016 a 2019, 2.856 (0,51\%) foram de recém-nascidos com algum tipo malformação congênita (MC). A maior prevalência foi das MC do aparelho osteomuscular, correspondendo a 40,4\%, esse é o tipo de MC mais prevalente no Brasil. De um modo geral, os resultados encontrados foram semelhantes aos da literatura atual. Considerando as variáveis dos recém-nascidos, 55,2\% eram do sexo masculino, cor parda (89,6\%) e $50.6 \%$ apresentou peso ao nascer entre $3.000 \mathrm{~g}$ a $4.000 \mathrm{~g}$, evidenciando que a maioria apresentou peso normal. Em relação às variáveis maternas, 56,1\% tinham entre 15 a 24 anos, nesse período as mães estão mais predispostas ao risco devido estarem na idade reprodutiva, quanto às consultas no pré-natal $45.7 \%$ realizaram sete ou mais consultas, em relação ao tipo de parto, $64 \%$ foi cesáreo e $49,1 \%$ por via vaginal. CONCLUSÃO: Foi possível caracterizar o panorama epidemiológico das malformações do aparelho osteomuscular. Essas informações são essências para o planejamento e intervenções em saúde, tendo como objetivos norteadores a prevenção e assistência, a fim de atender essa população e direcionar de forma eficiente os investimentos nessa área.

PALAVRAS-CHAVE: Anormalidades Congênitas; Epidemiologia; Recém-nascido. 


\section{REFERÊNCIAS}

DA COSTA, Tiago Sousa et al. Perfil epidemiológico das malformações congênitas do sistema nervoso central no estado do Pará, Brasil. Brazilian Journal of Health Review, v. 4, n. 1, p. 2765-2776, 2021.

OLIVEIRA, Samuel Machado; LÓPEZ, Mónica Lújan. Panorama epidemiológico de malformações congênitas no brasil (2013-2017). REVISTA SAÚDE MULTIDISCIPLINAR, v. 8, n. 2, 2020.

LIMA, Mauren Pimentel et al. Perfil De Malformação Congênita Em Nascidos Vivos, Do Estado Do Rio Grande Do Sul, 2012-2016. Revista de Saúde Dom Alberto, v. 3, n. 1, p. 105-120, 2019. 


\section{PERFIL EPIDEMIOLÓGICO DOS PACIENTES ATENDIDOS NO AMBULATÓRIO DE FISIOTERAPIA DA UNIVERSIDADE DO ESTADO DO PARÁ, CAMPUS SANTARÉM}

\section{Mayara Renata Lima Mota'; Thiago da Costa Alexandrino²; John Henry de Oliveira Vale ${ }^{3}$.}

${ }^{1}$ Universidade do Estado do Pará (UEPA). Santarém, Pará, Brasil; ${ }^{2}$ Universidade do Estado do Pará (UEPA). Santarém, Pará, Brasil; ${ }^{3}$ Universidade do Estado do Pará (UEPA). Santarém, Pará, Brasil.

INTRODUÇÃO: O ambulatório de fisioterapia do campus da Universidade do Estado do Pará (UEPA), em Santarém foi inaugurado há aproximadamente um ano com o objetivo de ajudar a suprir a carência de espaços para estágios, além de possibilitar ações de ensino e pesquisa. OBJETIVO: A pesquisa teve como objetivo traçar o perfil epidemiológico dos pacientes atendidos pelo ambulatório de fisioterapia. METODOLOGIA: A pesquisa caracteriza-se como observacional de caráter retrospectivo. A amostra foi composta de 64 prontuários, que corresponde ao número total de pacientes atendidos no período compreendido entre outubro de 2020 e setembro de 2021 . O critério para inclusão foi possuir prontuários fisioterapêutico completos e o critérios de exclusão foram possuir prontuários incompletos, ou fichas repetidos (fichas de reavaliação). A análise de dados ocorreu através de planilhas do Microsoft Excel Office 2013 (Windows), no qual se utilizou a estatística descritiva. RESULTADOS E DISCUSSÃO: O estudo revelou ser o sexo feminino o de maior prevalência nos atendimentos fisioterapêuticos, 62,5\% da amostra, a média de idade foi de 46,53 anos. A área mais procurada foi Traumatologia e Ortopedia com (70,5\%), com diagnóstico clínico mais presente foi de artrose e artrite reumatoide, lombalgia e pós-operatório de fraturas (32,2\%). Este estudo demonstrou que os diagnósticos encontrados, a faixa etária e o sexo acometido coincidem com o que a literatura apresenta. CONCLUSÃO: Conclui-se que este perfil epidemiológico contribuirá para que os fisioterapeutas conheçam cada vez mais as patologias que mais acometem a população, para assim atuar preferencialmente de maneira preventiva e melhorar a incidência destas doenças, proporcionando melhor qualidade de vida para a população.

PALAVRAS-CHAVE: Fisioterapia; Epidemiologia; Prevalência. 


\section{REFERÊNCIAS}

COSTA, Luana Karina de Almeida Nascimento et al. Unidade de Tratamento de Queimados: perfil epidemiológico dos pacientes admitidos na Fisioterapia. Revista Brasileira de Queimaduras, v. 12, n. 3, p. 177-181, 2013.

DA SILVA, Pedro Henrique Brito; DE ALMEIDA LIMA, Kallyandra; DE ALMEIDA LEROY, Patrícia Luz. Perfil epidemiológico dos pacientes assistidos na clínica de Fisioterapia Traumato-ortopédica da Prefeitura de Hidrolândia-Goiás. Revista Movimenta ISSN, v. 6, n. 3, p. 2013, 2013.;

DE OLIVEIRA, Josilene Cosmo et al. Perfil Epidemiológico dos pacientes atendidos em uma clínica-escola de fisioterapia na cidade de Maceió-AL. Interfaces Científicas-Saúde e Ambiente, v. 6, n. 2, p. 85-94, 2018. 


\title{
PERSPECTIVAS E DESAFIOS DAS METODOLOGIAS ATIVAS NA FORMAÇÃO FISIO- TERAPEUTICA: UM RELATO DE EXPERIÊNCIA DO INTERIOR DA AMAZÔNIA
}

\author{
Luandra Dias da Silva ${ }^{1}$; Israel Clemeson Moutinho Leite²; Vitória Maria Da Rold ${ }^{3}$; João Gus- \\ tavo Nascimento da Silva ${ }^{4}$; José Alexandre da Silva Júnior ${ }^{5}$. \\ 1,2,3,4,5 Universidade do Estado do Pará (UEPA). Santarém. Pará. Brasil.
}

INTRODUÇÃO: As metodologias ativas são processos interativos de conhecimento, análise, estudos, pesquisas e decisões individuais ou coletivas que têm base na ação didática, isto é, são métodos que solicitam a participação ativa dos estudantes. Desse modo, possuem diretrizes que orientam para a formação de profissionais com perfil generalista, humanista, crítico e reflexivo, e tem como eixo, um conjunto de áreas de competências que, articuladas, produzam os resultados esperados do profissional fisioterapeuta. OBJETIVO: Relatar as perspectivas e desafios encontrados por acadêmicos de fisioterapia referente as metodologias ativas. METODOLOGIA: Trata-se de um estudo qualitativo, descritivo, configurando-se em relato de experiência em que cinco acadêmicos do curso de fisioterapia (sujeitos do presente estudo) relataram suas perspectivas e desafios acerca da formação fisioterapêutica baseada nas metodologias ativas, vivenciadas no período de agosto a outubro de 2021, período que compreende o início da graduação dos sujeitos e o momento em que este estudo foi realizado. RESULTADOS E DISCUSSÃO: As metodologias ativas surgem com o intuito de transformar o modo de aprendizado do estudante, em que ele deixa de ser um ouvinte passivo e passa a ser agente ativo do conhecimento. Atualmente, apesar da grande presença da metodologia tradicional no processo educacional, há um significativo número de universitários que possuem considerável índice de aceitação das metodologias ativas devido aos benefícios proporcionados. Os sujeitos descreveram a importância do papel do aluno nesse método de ensino e citaram sua importância no desenvolvimento da oratória e na busca autônoma pelo conhecimento por meio de artigos científicos e livros. Entretanto, mencionaram ser um processo complexo, pois o ensino tradicional ainda predomina na educação e no aprendizado dos estudantes. No entanto, é perceptível a aceitação por esse método de ensino mesmo que o processo de adaptação possa ocorrer a passos lentos. CONCLUSÃO: Infere-se, portanto, que as metodologias ativas são agradáveis e, apesar dos impasses existentes como as dificuldades de adaptação a esse modelo, os pontos positivos prevalecem, tais quais: o aluno torna-se principal responsável pela busca do conhecimento e, com isso, deixa de ser um agente passivo e torna-se protagonista de sua formação acadêmica e profissional.

PALAVRAS-CHAVE: Metodologia; Educação em saúde; Formação Profissional em Saúde. 


\section{REFERÊNCIAS}

BERBEL, Neusi Aparecida Navas. As metodologias ativas e a promoção da autonomia de estudantes. Semina: Ciências sociais e humanas, v. 32, n. 1, p. 25-40, 2011.

DIESEL, Aline; BALDEZ, Alda Leila Santos; MARTINS, Silvana Neumann. Os princípios das metodologias ativas de ensino: uma abordagem teórica. Revista Thema, v. 14, n. 1, p. 268-288, 2017. EVANGELISTA, Izabel A. Soares; FERREIRA, Mª Antônia V. Por onde caminha à Docência Universitária. Curitiba: CRV, 2018. 


\title{
PREVALÊNCIA E CARACTERÍSTICAS DA NEOPLASIA MALIGNA DO COLO UTERI- NO NA REGIÃO DO BAIXO AMAZONAS PARAENSE
}

\author{
Israel Clemeson Moutinho Leite'; Andressa Letícia Ferreira Hora²; Flávia Hortência Gomes \\ de Oliveira ${ }^{3}$; Yana Bernarde Sá ${ }^{4}$; Mariana dos Anjos Furtado Sá5 \\ 1,2,3,4,5Universidade do Estado do Pará (UEPA). Santarém, Pará, Brasil.
}

INTRODUÇÃO: O câncer do colo do útero é um dos principais problemas de saúde pública da população feminina no mundo. Sabe-se hoje que a principal etiologia do câncer do colo do útero é a infecção pelo vírus do papiloma humano (HPV). Existem aproximadamente 100 tipos desse vírus capazes de infectar a espécie humana. O tipo histológico mais frequente é o carcinoma epidermóide, tipo mais incidente e que acomete o epitélio escamoso (80 a 90\% dos casos). OBJETIVO: Elaborar um levantamento acerca da neoplasia maligna de colo uterino na região do baixo amazonas enfatizando suas prevalências e características. METODOLOGIA: Trata-se de um estudo epidemiológico, descritivo, com abordagem quantitativa realizado a partir de dados secundários. Realizou-se uma pesquisa online através do Sistema de Informações Hospitalares do Sistema Único de Saúde (SIH-SUS), onde coletou-se dados do período entre janeiro de 2010 a dezembro de 2020. As variáveis foram: etnia, regime e caráter de atendimento, faixa etária, óbitos, taxa de mortalidade e valor total das internações. RESULTADOS E DISCUSSÃO: Na Região do Baixo Amazonas foram registrados 634 casos, com média anual de 63,4. Cerca de 16,7\% dos acometimentos (106) foram notificados em 2019, ano de maior incidência. Notou-se um decréscimo significativo no ano de 2020 podendo ser atribuído a falta de procura por serviços hospitalares durante a pandemia da Covid-19. Houve prevalência da neoplasia em mulheres pardas (83,5\%), com idade entre 40 a 59 anos $(53,6 \%)$, seguido de 20 a 39 anos $(28,7 \%)$. Quanto ao regime de atendimento, 59,1\% das internações foram urgentes, com prevalência de atendimento no setor público $(36,6 \%)$, porém houveram 390 casos com tal informação ignorada. Além disso, registrou-se 108 óbitos com uma taxa de mortalidade de 16,93, custando um valor total de R\$ 1.094.679,56 milhão por todas as internações. CONCLUSÃO: No Baixo Amazonas a neoplasia maligna do colo uterino acomete mulheres com idade entre 40 a 59 anos, pardas, atendidas no setor público, com predominância de internações urgentes, levando a uma alta taxa de mortalidade e elevados custos hospitalares. Assim, estudos mais aprofundados devem ser realizados para possibilitar prevenção, rastreamento e diminuição dos agravos causados pela doença.

PALAVRAS-CHAVE: Neoplasia do colo uterino; Epidemiologia; Internação hospitalar. 


\section{REFERÊNCIAS}

DE ALMEIDA, LIZ MARIA. Estudo dos genótipos do HPV e fatores associados ao diagnóstico do câncer do colo do útero em estádio inicial em mulheres atendidas na unidade de saúde de referência oncológica do Estado do Pará. Tese de Doutorado. UNIVERSIDADE FEDERAL DO PARÁ. 2016. Ministério da Saúde. Sistema de Informações Hospitalares do SUS (SIH/SUS). Acesso em: 23 set. 2021. Disponível em: http://tabnet.datasus.gov.br/cgi/deftohtm.exe?sih/cnv/nrpa.def

VAZ, Davis Wilker Nascimento et al. Avaliação Epidemiológica do Câncer do Colo do Útero no Estado do Amazonas. AMAZÔNIA: SCIENCE \& HEALTH, v. 8, n. 3, p. 61-69, 2020. 


\title{
PROTOCOLO DE FISIOTERAPIA CARDIORRESPIRATÓRIA APLICADO À PACIENTES PÓS-COVID 19: RELATO DE EXPERIÊNCIA
}

\author{
Ana Lúcia Farias Vidal'; Gabriela da Silva Pessoa ${ }^{2}$; Lucas Alexandre de Freitas ${ }^{3}$; Wanessa \\ Trindade de Souza ${ }^{4}$; Manoel Gionovaldo Lourenço ${ }^{5}$ \\ 1,2,3,4 e 5 Universidade do Estado do Pará (UEPA), Belém, Pará, Brasil.
}

INTRODUÇÃO: No final de 2019, um novo tipo de vírus surgiu na cidade de Wuhan (China), pertencente à família Coronaviridae. Identificado como a "síndrome respiratória aguda grave do coronavírus 2" (SARS-CoV-2) ou mundialmente conhecido como COVID-19 que desenvolve sinais e sintomas como: febre, tosse, dor de cabeça, fadiga, congestão das vias aéreas superiores e entre outros. Além disso, disfuncionalidades podem ocorrer no sistema cardiovascular pela COVID-19. Houve relatos de arritmias, lesão cardíaca aguda, taquicardia e uma alta carga de doença cardiovascular concomitantes nos infectados. Além desses acometimentos, a COVID-19 pode afetar o sistema respiratório causando: dispneia, hipoxemia, cianose, taquipneia, dor torácica, e necessidade de ventilação mecânica. Com base nessas repercussões, houve a elaboração de um projeto de pesquisa por parte da Unidade de Ensino e Assistência de Fisioterapia e Terapia Ocupacional (UEAFTO/UEPA) para o atendimento de indivíduos acometidos por sequelas pós-infecção da COVID-19. OBJETIVO: relatar a experiência obtida durante as visitas técnicas ao ambulatório cardiorrespiratório da UEAFTO. METODOLOGIA: Estudo observacional, transversal e descritivo realizado numa unidade de reabilitação para pacientes, pós infectados pela COVID-19 com complicações cardiorrespiratórias. Os pacientes foram submetidos a consulta inicial onde foram avaliadas questões relativas à qualidade de vida e condições físico-funcionais utilizando-se a manovacuometria, a espirometria, o teste de caminhada de 6 minutos e o índice de Borg. Utilizou-se de um protocolo com os seguintes recursos terapêuticos: esteira ergométrica, bicicleta estacionária, treinamento muscular respiratório e estação de treinamento da força muscular para os membros superiores e inferiores. Os atendimentos tiveram duração de uma hora por sessão, com dois atendimentos semanais, em um total de 10 semanas contabilizando 20 sessões. RESULTADOS E DISCUSSÃO: Relatos discorridos pelos pacientes compuseram o primeiro grupo do estudo demonstraram evolução benéfica nos sinais e sintomas, tais como, diminuição de dores ao respirar, palpitações e arritmias. A aplicabilidade do protocolo proporcionou a readaptação, reabilitação e condicionamento dos pacientes à retomada gradativa de suas atividades diárias, ratificando a atuação do fisioterapeuta. CONCLUSÃO: Os relatos nos permitiram perceber a necessidade da manutenção de um suporte de reabilitação cardiorrespiratória aos pacientes pós-COVID 19.

PALAVRAS-CHAVE: Cardiorrespiratória; COVID-19; Fisioterapia. 


\section{REFERÊNCIAS}

CESPEDES, Mateus da Silveira; SOUZA, José Carlos Rosa Pires de. Sars-CoV-2: A clinical update-II. Revista da Associação Médica Brasileira, v. 66, p. 547-557, 2020.

FERRARI, Filipe. COVID-19: dados atualizados e sua relação com o sistema cardiovascular. Arquivos Brasileiros de Cardiologia, v. 114, p. 823-826, 2020.

FERNANDES, Fábio et al. Afecções pericárdicas em pacientes com COVID-19: uma possível causa de deterioração hemodinâmica. Arquivos Brasileiros de Cardiologia, v. 115, p. 569-573, 2020.

Santos BSF, Silva WFF, Felix PT. O vírus SARS-CoV-2 e sua ação no sistema cardiovascular: uma revisão de literatura. Acesso em 30 de setembro de 2021. Disponível em: https://univisa.edu.br/wp-content/uploads/2020/10/Artigo-1.-O-v\%C3\%ADrus-SARS_CoV_2-e-sua-a\%C3\%A7\%C3\%A3o-no-sistema-cardiovascular_uma-revis\%C3\%A3o-de-literatura.pdf.

SILVA, Rodrigo Marcel Valentim da; SOUSA, Angelica Vieira Cavalcanti de. Fase crônica da COVID-19: desafios do fisioterapeuta diante das disfunções musculoesqueléticas. 2020. 


\title{
REABILITAÇÃO DE PACIENTES COM SEQUELAS DA COVID-19 EM UMA ORGANIZAÇÃO NÃO GOVERNAMENTAL NO MUNICÍPIO DE ITAITUBA: RELATO DE EXPERIÊNCIA
}

\author{
Ione Pontile Matias da Silva'; Rafael Moab Sousa dos Santos². \\ ${ }^{1,2}$ Faculdade de Itaituba (FAI). Itaituba, Pará, Brasil.
}

INTRODUÇÃO: O coronavírus é caracterizado como um RNA vírus da ordem Nidovirales, da família Coronaviridae. Dentre os tipos descritos, o SARSCoV-2 é o coronavírus que ocasiona a doença chamada de COVID-19. Dentre as manifestações clínicas mais comuns, encontram-se a tosse, dor de garganta, coriza e/ou dificuldade respiratória, caracterizando a doença como uma Síndrome Gripal. Na ocorrência de casos graves, considera-se a presença da Síndrome Respiratória Aguda Grave (SRAG), manifestando dispneia, pressão persistente no tórax e queda na saturação periférica de oxigênio (SpO2) em ar ambiente, onde o processo sintomatológico ocorre, em média, de 5 a 6 dias após a infecção, em um ciclo de 1 a 14 dias. Passado o período infeccioso, tem-se observado sequelas sistêmicas, sendo necessária a intervenção fisioterapêutica. OBJETIVO: Relatar a experiência da reabilitação fisioterapêutica no pós COVID-19 em uma instituição que oferece serviços gratuitos à comunidade carente do município. METODOLOGIA: Trata-se de um relato de experiência com abordagem qualitativa proveniente do estágio supervisionado da Faculdade de Itaituba realizado na ONG Ação Sorriso, vivenciado no mês de fevereiro de 2021. Foram realizadas anamnese, exame físico e avaliação funcional dos pacientes para verificação das sequelas motoras e cardiorrespiratórias. Como instrumento de análise, usou-se a Escala de BORG para a percepção de esforço. RESULTADOS E DISCUSSÃO: Neste período, houve atendimentos em pacientes com sequelas pós Covid-19 sendo realizadas intervenções através de exercícios respiratórios com e sem associação à cinesioterapia ativa em MMSSII e treino de marcha associado ao equilíbrio dinâmico. A reavaliação se deu após 5 sessões de fisioterapia, onde observou-se alcance dos objetivos a médio prazo, havendo redução na pontuação da escala de BORG e da frequência respiratória, e consequente aumento da $\mathrm{SpO}$, podendo assim, perceber as evoluções obtidas através das intervenções realizadas. CONCLUSÃO: A partir da experiência, constatou-se a necessidade da fisioterapia para pacientes carentes na comunidade, tendo em vista a importância dessa abordagem na melhora da qualidade de vida e retorno às atividades funcionais presentes antes da infecção pela Covid-19. Proporcionando, ainda, o estímulo para observar a importância do fisioterapeuta em todas as fases da doença, em especial, na fase da reabilitação da função.

PALAVRAS-CHAVE: Coronavírus; Sequelas; Reabilitação. 


\section{REFERÊNCIAS}

ISER, Betine Pinto Moehlecke et al. Definição de caso suspeito da COVID-19: uma revisão narrativa dos sinais e sintomas mais frequentes entre os casos confirmados. Revista Epidemiologia e Serviços de Saúde, Brasilia, 2020.

LIMA, Claudio Márcio Amaral de Oliveira. Informações sobre o novo coronavírus (COVID-19). Colégio Brasileiro de Radiologia e Diagnóstico por Imagem, Rio Janeiro, 2020.

NETO, Antônio Rosa de Sousa et al. Manifestações sintomáticas da doença causada por coronavírus (COVID-19) em adultos: revisão sistemática. Revista Gaúcha de Enfermagem, v.42, 2021. 


\title{
REABILITAÇÃO FISIOTERAPÊUTICA EM ÍNDIVIDUOS JOVENS DIAGNOSTICADOS COM CÂNCER ÓSSEO
}

\author{
Lizandra Melo de Araújo; ; Iana Beatriz Castro Batista ${ }^{2}$; Taynara de Oliveira Ferreira ${ }^{3}$; Lei- \\ giane Alves Cardoso ${ }^{4}$. \\ ${ }^{1,2,3,4}$ Universidade Nilton Lins (UNL). Manaus, Amazonas, Brasil.
}

INTRODUÇÃO: Osteossarcoma é uma neoplasia maligna sem causa definida, condições genéticas e hereditárias, são condições que tornam os indivíduos mais suscetíveis a desenvolver esse tipo de câncer, sendo seu alvo células osteogênica. Imobilidade, dor óssea, compressão da medula espinhal, fratura patológica ou hipercalcemia, são sintomas que se manifestam. OBJETIVO: Evidenciar a atuação do fisioterapeuta nos atendimentos de indivíduos jovens diagnosticados com câncer ósseo "osteosarcoma". METODOLOGIA: Trata-se de uma revisão da literatura. Os dados coletados são originários de artigos científicos, revistas científicas da área da fisioterapia: (BVS - Bireme) Biblioteca Virtual de Saúde, Secad - Secretaria de Educação a Distância, (SciELO) - Scientific Eletronic Library Online; e (MedLine) - Literatura Internacional em Ciências da Saúde. Para o embasamento deste trabalho foram utilizados 14 artigos. RESULTADOS E DISCUSSÃO: Dentre os artigos encontrados a um consenso que a população mais atingida são adolescentes na faixa etária entre 10 a 16 anos, decorrente do processo de desenvolvimento e outros fatores. O uso de técnicas especifica trouxe resultados satisfatórios na reabilitação dos movimentos como também em quadros de dor, trazendo melhores na capacidade funcional e respiratória do indivíduo. A fisioterapia vem ganhando destaque na área oncológica, pois aos poucos proporciona aos indivíduos o retorno as suas atividades, melhorando a autoestima. Resultados consideravelmente satisfatórios ocorreram através da aplicação de atividades de baixa intensidade, influenciando nas respostas psicológicas apresentadas pelo paciente no decorrer do tratamento. Um estudo de 2018 relata que os indivíduos apresentam respostas positivas a sintomas psicológicos que possam aparecer no decorrer do tratamento quando os mesmos são submetidos a recursos terapêuticos, além disso, mostram resultados melhores quando se faz aplicabilidade de atividades de baixa intensidade comparando a aplicação de atividades de alta intensidade. CONCLUSÃO: É necessário que se aprofunde em mais pesquisas, no que se diz respeito sobre o papel do fisioterapeuta, para que os mesmos saibam da importância deste profissional atuando nesta área. Obtendo melhorias na qualidade de vida destes indivíduos através das práticas, e dos recursos fisioterapêuticos.

PALAVRAS-CHAVE: Osteossarcoma; Anos de vida ajustados por qualidade de vida; Fisioterapia. 


\section{REFERÊNCIAS}

GOMES B, et al: Dos Sintomas ao Tratamento: Considerações Sobre Itinerário Terapêutico no Câncer Infanto-juvenil.2018. Revista de Serviço Social - UNIGRANRIO.

INCA: Instituto Nacional do Câncer. 2019.

MARECHAEL et al: Effect of mixed-exercise programo n physical capacity and sedentary behavior older adults during câncer treatments. Aging Clin Exp Rev, 2019;31:1583-1589.

SILVA L, et al: The Physio Therapist Role In The Palliative Care Team In The Service To Cancer Patiente. 2017 - Rev: Unimontes Cientifica. ISSN 2236-5257). 


\title{
REABILITAÇÃO RESPIRATÓRIA PÓS COVID-19: PRÁTICAS FISIOTERÁPICAS A PARTIR DO MÉTODO DE TELEREABILITAÇÃO
}

\author{
Arlisson Rocha dos Reis'; Izabel Alcina Soares Evangelista². \\ 1,2Universidade do Estado do Pará (UEPA). Santarém. Pará. Brasil.
}

INTRODUÇÃO: Com o surgimento da pandemia SARS-CoV-2 a telereabilitação se tornou um método importante aos fisioterapeutas para a realização do tratamento reabilitador em pacientes com sequelas respiratórias pós covid-19. Nesse sentido, a atuação desse profissional tem respaldo por meio da resolução $n^{\circ} 516$ de 20 de março de 2020 que autoriza as práticas fisioterápicas através das modalidades de teleconsulta, teleconsultoria e telemonitoramento. OBJETIVO: Investigar a atuação do fisioterapeuta na reabilitação de pacientes com problemas respiratórios pós alta hospitalar da covid-19, a partir do método telereabilitação. METODOLOGIA: Os dados coletados dessa revisão foram encontrados em artigos científicos publicados entre os anos de 2020-2021, pesquisados a partir das ferramentas do Google acadêmico e SciELo. Logo, fez-se a aplicação dos descritores: "Telereabilitação", "Fisioterapia", "Reabilitação Respiratória" e "Covid-19”, e equivalente em inglês. Por conseguinte, considerou-se os critérios de inclusão: os estudos que abordam as sequelas respiratórias decorrentes da covid-19 e reabilitação respiratória, bem como, a telereabilitação como uma alternativa ao tratamento reabilitador, e de exclusão, estudos com outras abordagens com o uso da telereabilitação, que não tratavam sobre as sequelas respiratórias pós covid-19 e textos com outros períodos de publicação e/ou idioma. Foram encontrados 89 artigos dos quais apenas 04 respeitaram os critérios. RESULTADOS E DISCUSSÃO: Dessa forma, essa estratégia tem como característica o uso da tecnologia de comunicação à distância e pode ser realizada de maneira síncrona e/ou assíncrona. Ademais, detectou-se a importância do fisioterapeuta em se preocupar com a segurança de dados e protocolos de privacidade relativos as coletas, armazenamentos e compartilhamento de dados do paciente; de verificar a segurança do local para a prática dos exercícios; prescrever atividades especificas a cada paciente, possibilitando sua realização de forma supervisionada por videoconferência em tempo real; reavaliar o paciente via telemonitoramento. CONCLUSÃO: Desse modo, percebe-se que a atuação do fisioterapeuta por meio da telereabilitação se tornou objeto de estudo para muitos pesquisadores. Isso, por possibilitar os serviços fisioterápicos a partir de tecnologias de comunicação à distância. Portanto, acredita-se que tratamentos fisioterápicos com o uso das tecnológicas de comunicação persista após o período da covid-19 como uma nova tendência à atuação dos profissionais da fisioterapia.

PALAVRAS-CHAVE: Telereabilitação; Sequelas Respiratórias; Covid19. 


\section{REFERÊNCIAS}

CANDIDO, Natalie et al. Atendimentos não presenciais em fisioterapia durante a pandemia por COVID-19: uma reflexão sobre os desafios e oportunidades no contexto brasileiro. SciELO Preprints, 2021.

SANTANA, André Vinícius et al. Reabilitação pulmonar pós-COVID-19. J Bras Pneumol. 2021;47(1):e20210034.

SANTOS, Airton dos et al. Reabilitação pós covid-19. Subsecretaria de Saúde Gerência de Informações Estratégicas em Saúde CONECTA-SUS. 17 de novembro de 2020.

SILVA, Lidia Cristina de Oliveira et al. Sequelas e reabilitação pós-covid19: revisão de literatura. Revista das Ciências da Saúde e Ciências aplicadas do Oeste Baiano-Higia. 2021; 6(1):169-184. 


\title{
RELEVÂNCIA DA INSERÇÃO EFETIVA DA FISIOTERAPIA NO PROGRAMA SAÚDE NA ESCOLA-PSE: REVISÃO DE LITERATURA.
}

\author{
Richardson Rodrigues Gutterres ${ }^{1}$; Amanda Eduarda da Costa Sousa ${ }^{2}$; Ellen Cristina da Silva \\ Medeiros $^{3}$; Soly Guedes de Oliveira ${ }^{4}$; Tatiane Bahia do Vale Silva ${ }^{5}$. \\ 1,2,3,4,5 Universidade do Estado do Pará (UEPA). Tucuruí, Pará, Brasil.
}

INTRODUÇÃO: É de suma importância que a atuação do fisioterapeuta não se vincule apenas a hospitais e centros de reabilitação, pois a inserção deste profissional em outros setores, em destaque no ambiente escolar, mostra-se relevante no que tange a promoção em saúde coletiva. Instituído em 2007, o Programa Saúde na Escola-PSE visa contribuir para a formação integral dos estudantes através de ações de promoção, prevenção e atenção à saúde, sendo voltado para situações de vulnerabilidade que comprometem o pleno desenvolvimento de crianças e jovens da rede pública de ensino. Denotase que a inclusão da fisioterapia nessa esfera garante, através da prevenção, uma melhora em doenças relacionadas à postura, em relação as cargas excessivas de mochilas utilizadas. Sendo assim, um estudo de acordo com idade e peso e suas medidas antropométricas é utilizado na fisioterapia para possibilitar a investigação de encurtamento de membros e disfunções cinético-funcionais. OBJETIVO: Reunir evidências na literatura atual sobre a relevância da inserção efetiva do Fisioterapeuta no Programa Saúde na Escola (PSE), através de uma revisão sistemática. METODOLOGIA: Revisão e estudo de literatura a partir de periódicos e artigos científicos sobre o tema nos bancos de dados online SCIELO, PEDro e PubMed, além de livros e revistas científicas publicadas no período de 2014 a 2021. RESULTADOS E DISCUSSÃO: Foram encontrados 10 artigos, sendo 5 selecionados, pois fazem ligações mais claras e específicas sobre a importância da fisioterapia aplicada no contexto da promoção em saúde no ambiente escolar. Desse modo, poucos são os estudos publicados a respeito deste assunto, mas dentre os estudos encontrados existe a conformidade de opiniões entre os autores. CONCLUSÃO: Portanto, através da pesquisa, denota-se que é primordial a participação dos profissionais de fisioterapia no contexto escolar para que as medidas de intervenções tomadas auxiliem na mudança de maus hábitos e posturas inadequadas realizadas não só pelas crianças, mas também por professores, amigos e familiares.

PAlAVRAS-CHAVE: Atenção Primária; Acesso aos Serviços de Saúde; Prevenção Primária. 


\section{REFERÊNCIAS}

DE LIMA BORGES, Larissa; NOGUEIRA, Edna Lívia; CARVALHO, Lívia Batista Silva. Avaliação postural e educação em saúde na Escola Morro do Sansão, Sobradinho 2/DF: a fisioterapia na atenção básica. CADERNOS DE EDUCAÇÃO, SAÚdE E FISIOTERAPIA, v. 3, n. 6, 2016.

DOS PRAZERES, Livio Matheus Aragão et al. Vivência de uma ação intersetorial por discentes de fisioterapia no Programa Saúde na Escola (PSE). CADERNOS DE EDUCAÇÃo, SAÚDE E FISIOTERAPIA, v. 1, n. 1, 2014.

NETO, Elísio Alves Peireira et al. Saúde na escola: reflexões a partir das vivências dos estudantes de Fisioterapia. Tempus Actas de Saúde Coletiva, v. 10, n. 1, p. ág. 231-239, 2016.

RODRIGUES, François Talles Medeiros et al. Atuação da fisioterapia no Programa Saúde na Escola-PSE do município de João Pessoa/PB. CADERNOS DE EDUCAÇÃO, SAÚDE E FISIOTERAPIA, v. 1, n. 1, 2014. 
editoraomnisscientia@gmail.com https://editoraomnisscientia.com.br/

@editora_omnis_scientia 
editoraomnisscientia@gmail.com https://editoraomnisscientia.com.br/

@editora_omnis_scientia

(2) https://www.facebook.com/omnis.scientia.9 f

$$
\text { +55 (87) 9656-3565 }
$$

